\title{
Parametric insurance and technology adoption in developing countries*
}

\author{
Enrico Biffis ${ }^{\dagger} \quad$ Erik Chavez $^{\dagger} \quad$ Alexis Louaas $^{\ddagger} \quad$ Pierre Picard $^{\ddagger}$
}

November 5, 2020

\begin{abstract}
Technology adoption is crucial for the development of low income countries. This paper investigates how parametric insurance can contribute to improving access to finance, and hence to technology, for smallholder farmers. In a model with moral hazard, we show that bundling parametric insurance with loans may lower collateral requirements, thus promoting the financial inclusion of poor households. The case of agricultural input loans and weather-index insurance is studied in detail and related to bundled finance solutions recently piloted among smallholder farmers in Tanzania.
\end{abstract}

JEL classification: G22, O16, 031, Q14

Key words: parametric insurance; crop insurance; moral hazard; credit rationing; technology adoption

Conflict of Interest: The authors declare that they have no conflict of interest

\footnotetext{
*The support of the Climate Justice Resilience Fund (WINnERS Diversity Plus Programme), Climate-KIC/European Institute of Innovation and Technology (ARISE project), and African Development Bank (DAFS project) are gratefully acknowledged. We would like to thank Luc Christiaensen, Alejandro Del Valle, Glenn Harrison, Alex Muermann, Calum Turvey, and Joachim Vandercasteelen for helpful feedback, as well as Nicomed Bohay, Ananth Raj, Shanoo Saran, and Donald Wilson for support on the ground.

${ }^{\dagger}$ Biffis (e.biffis@imperial.ac.uk) and Chavez (erik.chavez@imperial.ac.uk) are at the Brevan Howard Centre for Financial Analysis, Imperial College Business School, South Kensington Campus, London SW7 2AZ, United Kingdom.

${ }^{\ddagger}$ Louaas (alexis.louaas@polytechnique.edu) and Picard (pierre.picard@polytechnique.edu) are at CREST, Ecole Polytechnique, Paris, France.
} 


\section{Introduction}

The adoption of increasingly efficient technologies has undoubtedly played a major role in the long-run economic evolution of countries which by now we regard as being developed. In particular, agricultural productivity has achieved considerable gains in many Western and Asian countries by adopting hybrid, high-yield seeds during the second part of the twentieth century, by relying on the construction of reliable irrigation systems, and by appropriately using fertilisers and pesticides. These achievements are part of broader efforts associated with a green revolution aimed at ensuring global food security by promoting more efficient agricultural production technologies and usually going under the name of Green Revolution (e.g., Conway and Toenniessen, 1999). Such revolution has certainly contributed to improving the living conditions of the many and in particular of the poorer (Parente and Prescott, 1994, Evenson and Gollin, 2003), but important challenges remain and have prevented, for example, many sub-Saharan African countries from participating in the productivity gains experienced elsewhere (Freebairn, 1995; Pingali, 2012).

Barriers to technology adoption have been investigated by several scholars (e.g., Duflo et al., 2008, Suri, 2011, among others), and have been ascribed to behavioural biases (e.g., Duflo et al., 2011), information diffusion bottlenecks (e.g., Foster and Rosenzweig, 1995), Bandiera and Rasul (2006), and credit constraints (e.g., Dercon and Christiaensen, 2011, Karlan et al. 2014). In this paper, we focus on the latter and consider the emerging use of bundled finance solutions to promote extension of credit to support technology adoption. These solutions bundle loans with insurance and extension services possibly supported by mobile technology. In an empirical investigation carried out in Ethiopia, Dercon and Christiaensen (2011) found that, in the presence of credit constraints, the prospect of very low returns due to adverse weather conditions was an important driver of low rates of technology adoption. Hence a potentially valuable role for insurance to facilitate technology adoption by mitigating exposure to weather shocks. This rationale also motivates Shee and Turvey (2012)'s call for providing credit with insurance against meteorological hazards. However, indemnity insurance is difficult to scale in developing countries due to high servicing costs and moral hazard problems. This favours the introduction of hybrid products with a parametric insurance component, which usually insures lenders against default risk and/or smallholder farmers against weather shocks. An example is discussed in detail in section 3. The evidence on the success of these solutions is still mixed. Studies by Carter et al. (2014), McIntosh et al. (2013), Cole et al. (2017), and Hill et al. (2019), for example, find an overall positive effect of insurance on technology adoption. In contrast, preliminary results (baseline and first wave) from an experiment in Kenya, presented in Ndegwa et al. (2019), reveal little effect of combining insurance with credit 
on take-up rates. Giné and Yang (2009), on the other hand, find a negative effect of insurance on technology adoption 1

In this paper, we develop a model of credit rationing where the farmer can strategically default and/or misuse the loan. This ex-post and/or ex-ante moral hazard model allows us to clarify when and how parametric weather insurance can relax collateral constraints and promote access to credit and hence technology adoption. The model is motivated by products piloted in Tanzania during the last few years and allowing smallholder farmers to use parametric insurance as a form of credit enhancement to gain access to input loans (see section 3). There, parametric insurance acts as a substitute for collateral or credit history, thus promoting financial inclusion and adoption of more productive input packages. As is well known, parametric insurance entails basis risk, i.e., the risk of mismatch between the actual exposure of the insured and the insurance contract's payout. The literature has traditionally focused on the efficiency losses induced by basis risk via imperfect risk sharing and dampened insurance demand (e.g., Clarke, 2016) ${ }^{2}$ without necessarily acknowledging the efficiency gains which may arise from an imperfect insurance contract alleviating other frictions. In contrast, our model clarifies the mechanism allowing parametric insurance to overcome credit rationing, and provides theoretical grounding for some initiatives taking place in East Africa.

In practice, another limit to the welfare gains that can be expected from parametric insurance is farmers' ambiguity aversion 3 The effect of ambiguity aversion on the demand for parametric insurance is approached by Bryan (2019) from both a theoretical and applied perspective. In particular, through two RCTs conducted in Malawi and Kenya, he highlights how ambiguity-averse farmers struggle to assess whether insurance contracts reduce risk, a problem which is most pronounced when the efficiency gain from production technology is ambiguous. For our part, we will discuss how the incentives of farmers and their expected profit from investment may be affected by their lack of trust in the insurance mechanism and by their ambiguity aversion in extensions of our model.

The rest of the paper is organised as follows. A model of credit rationing under moral hazard is presented in Section 2. Ex-post and ex-ante moral hazard are considered in turn. In each case, we show how paramet-

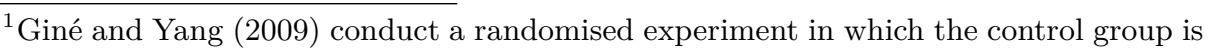
proposed a loan to purchase improved seeds and crops without insurance. The treatment group in contrast, is required to purchase an actuarially fair insurance policy. The authors find that fair insurance is associated with a lower take-up, a result that they explain by the cognitive cost of evaluating the insurance.

${ }^{2}$ The fact that contract non-performance may decrease insurance demand has been pointed out previously by Doherty and Schlesinger (1991).

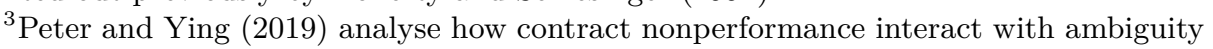
aversion, and they determine sufficient conditions under which a more pessimistic belief and greater ambiguity decrease the optimal demand for insurance.
} 
ric insurance bundled with loan contracts leads to a decrease in required collateral levels, thereby allowing a wider access to technology adoption. Section 3 presents a calibration of the model capturing the main features of products recently piloted in Tanzania. Technological scenarios and a parametric insurance mechanism are described. Calibrations illustrate the effect of insurance on the access to credit. The final Section concludes and an Appendix provides additional information on crop modelling under various technological scenarios.

\section{The model}

Following the seminal papers of Jaffee and Russell (1976) and Stiglitz and Weiss (1981), the role played by information asymmetry in rationing credit has been highlighted by several authors. Our analysis is related to the approach of Holmstrom and Tirole (1997), in that it links credit rationing to insufficient pledgeable wealth available to prospective borrowers in a setting with moral hazard. We focus on the mechanisms through which parametric insurance leads to a relaxation of this wealth constraint, in the form of lower collateral requirements.

We model a lender-farmer relationship with two versions of the same baseline model differing along the moral hazard dimension. In the first version, we focus on ex-post moral hazard: credit is indeed used in the intended way, but output is private information to the farmer, who may therefore side-sell production in parallel markets and strategically default. As verifying output may be costly, the lender may prefer to require the posting of collateral to incentivize loan repayment. Collateral unavailability may hence result in financial exclusion and the impossibility to adopt the target technology.

In the second version of the model, we focus on ex-ante moral hazard: credit is extended to fund technology adoption, but the actual use of funds (and hence technology adoption) is private information to the borrower, who may therefore decide to consume the credit or use it in unproductive ways for private benefit, thus lowering the probability of debt repayment. To incentivize the farmer to use funds productively, the lender therefore requires the posting of collateral, which may not be available to a smallholder farmer.

In brief, ex-ante moral hazard is related to the use of funds allocated by the bank, ex-post moral hazard arises because the farmer may strategically default. Irrespective of the type of moral hazard considered, the model has a common baseline structure, with two dates, 0 and 1, and risk-neutral agents (farmers and banks). The risk-free interest rate is assumed to be zero for convenience. There is a continuum of farmers, and at time 0 , each of them can engage in a project by adopting a technology requiring investment of capital $I$ at time 0 , and yielding at time 1 random income $\tilde{R}$, which takes 
a value of $R$ with probability $1-p$ (the project is successful), and 0 with probability $p \in[0,1]$ (the project fails). Farmers have no liquid resources to finance the new technology, and thus require a loan to support capital investment $I$. Banks agree to grant loans with expected profit no lower than $\eta \geq 0$, the case $\eta=0$ corresponding to a perfectly competitive credit market, the case $\eta>0$ to monopolistic competition. At time 1, farmers must return the principal $I$ and the interest amount $I r$, where $r$ is the interest rate required by the lender. At time 0, each farmer owns an illiquid asset $A$ that can be used as collateral, but cannot be used to fund the project. The value of $A$ differs among farmers. In order to mitigate the prospect of default, the bank requires a collateral of amount $C$ to be posted at time 0 , with the agreement that it will be returned at time 1, provided the loan is repaid in full. Farmers also have access to other resources, called $\omega$, generated from activities in the informal sector, which are not verifiable and cannot be used as collateral but can be used to pay the insurance premium when required. In variants of our model, we will also show how our conclusions can be extended to the case where farmers do not own any asset (i.e., $A=0$ for all farmers) and therefore loan contracts cannot include collateral requirements.

Production losses (in our model, the project is unsuccessful) are driven by an exogenous risk factor, which may be thought of as a weather shock and is modelled by a binary random variable $\tilde{y}$ taking values in $\{0,1\}$, with $\mathbb{P}(\tilde{y}=$ $1)=q \in(0,1)$. The events $\{\tilde{y}=0\}$ and $\{\tilde{y}=1\}$ capture favourable and adverse weather conditions, respectively. The random variable $\tilde{y}$ may be a farm-specific idiosyncratic risk or may be correlated among farmers. Should the farmer face a loss, default occurs and the lender seizes the collateral $C$.

The joint distribution of the index $\tilde{y}$ and the income $\tilde{R}$ is given by

$$
\begin{aligned}
& \mathbb{P}(\tilde{R}=0 \mid \tilde{y}=1)=f+\varepsilon \\
& \mathbb{P}(\tilde{R}=0 \mid \tilde{y}=0)=f,
\end{aligned}
$$

where we assume $\varepsilon>0,0<f<1$, and $f+\varepsilon<1$. In words, the occurrence of the weather shock leads to an increase in the probability of failure equal to $\varepsilon$. When $\varepsilon=0$, the weather shock is uninformative about the farmer's income, whereas when $f=0$ and $\varepsilon=1$ the weather shock is perfectly correlated with the farmer's income. As $\tilde{y}=1$ or 0 with probability $q$ and $(1-q)$, respectively, we have $p=f+q \varepsilon$. 


\begin{tabular}{|c|c|c|c|}
\hline & \multicolumn{2}{|c|}{$\tilde{y}$} & \\
\hline & 0 & 1 & \\
\hline & $(1-q)(1-f)$ & $q(1-f-\varepsilon)$ & $1-p$ \\
\hline 0 & $(1-q) f$ & $q(f+\varepsilon)$ & $p$ \\
\hline & $1-q$ & $q$ & 1 \\
\hline
\end{tabular}

Table 1: Conditional joint and marginal distributions of the project outcome and weather shock.

\section{$2.1 \quad$ Ex-post moral hazard}

In this section, the farmer always makes the intended use of the loan : she purchases the technology and follows the optimal usage instructions. However, the outcome of the project is known by the farmer only, who may therefore decide to report a low income and go bankrupt to avoid reimbursing. When she does so, she incurs a cost $F$, which may reflect a non pecuniary cost akin to the cost of bankruptcy in Diamond (1984). $F$ may also reflect a moral cost incurred by a farmer who cheats on the contracts. Bolton and Scharfstein (1990), Gromb (1994) and Dewatripont and Maskin (1995) have also shown how this cost could be microfounded in multi-period models with the threat of termination of a credit line.

We assume the following three assumptions to hold:

$$
\begin{array}{r}
N P V=(1-p) R-I \geq \eta, \\
F \geq I, \\
I+\eta>(1-p) F .
\end{array}
$$

Hypothesis (H1) guarantees that the project's Net Present Value $(N P V)$ meets the expected profit required by the bank. Hypothesis $(\mathrm{H} 2)$ allows the incentive compatibility to hold for some values of the parameter space (if $F<I$, the farmer always prefers to default). We show hereafter that Hypothesis (H3) guarantees that a positive collateral is indeed required to prevent cheating by the farmer in the absence of insurance.

\section{Case without insurance}

We begin by presenting the case of a traditional loan, not bundled with an insurance contract. The incentive compatibility constraint of the farmer and the participation constraint of the bank are written as

$$
\begin{array}{r}
F \geq D-C, \\
(1-p) D+p C-I \geq \eta,
\end{array}
$$


respectively, where $D=(1+r) I$ is the nominal debt of the farmer. The participation constraint can also be written as

$$
r \geq \frac{(I-C) p+\eta}{I(1-p)}
$$

Figure 1 shows the set of feasible contracts in the $(D, C)$ plane. The points on segment $[J, E]$ provide the farmer with the same level of expected income $\mathbb{E} W=N P V-\eta>0$ by assumption $(H 1)$. The set of feasible contracts lies above the $I C 1$ and $P C 1$ curves and is characterised by

$$
\begin{aligned}
& C \geq I+\eta-F(1-p)=C_{1}^{N} \\
& r \leq \frac{p F+\eta}{I}=r_{1}^{N} .
\end{aligned}
$$

The two inequalities are binding at point $E$, where the collateral reaches its smallest value, $C_{1}^{N}$.

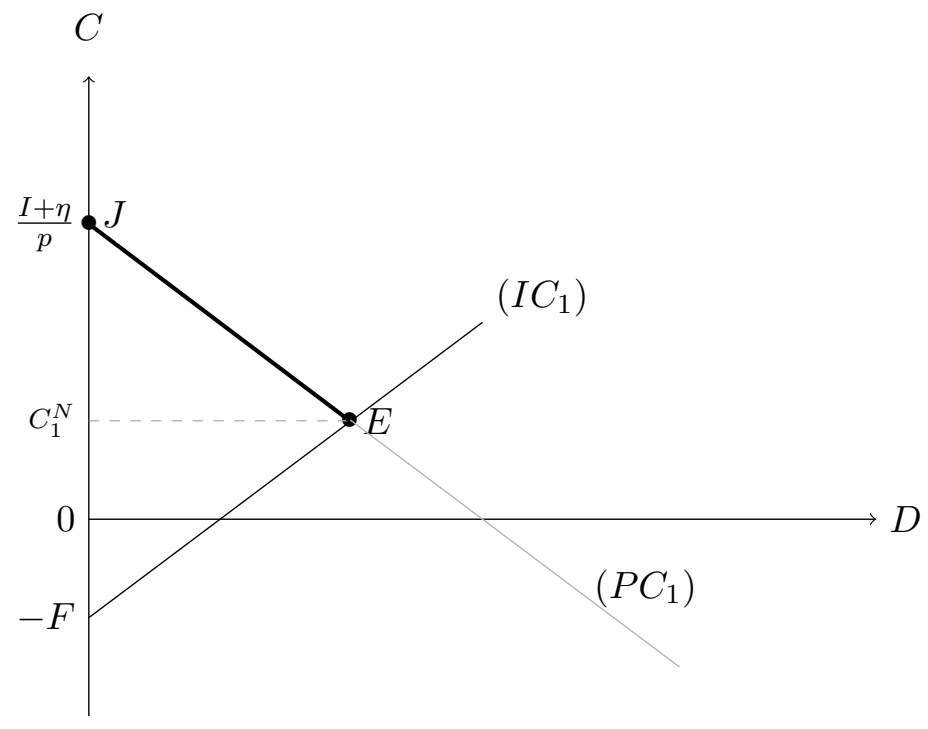

Figure 1: Ex-post moral hazard. Feasible contracts without insurance. Contracts are depicted in the $(D, C)$ plane. The points on segment $[J, E]$ provide the farmer with the same level of expected income $\mathbb{E} W=N P V-\eta \geq 0$. Inequalities (1)-(2) are binding at point $E$, where the collateral reaches its smallest value, $C_{1}^{N}$.

\section{Case with parametric insurance}

We now consider the case of a parametric insurance paying $D$ to the lender when $\tilde{y}=1$, in which case it exempts the farmer from her obligation to repay the loan. The insurance contract pays nothing when $\tilde{y}=0$. The loan contract stipulates that the farmer receives her collateral back when 
the loan is repaid, either by the farmer, when $\widetilde{R}=R$ and $\widetilde{y}=0$, or by the insurer, when $\widetilde{y}=1$ (and $\widetilde{R}=0$ or $R$ ). The contract between the lender and the farmer stipulates these clauses, meaning that the loan and insurance components are bundled in the same contract. Finally, the actuarially fair insurance premium, $P$, is paid by the farmer to the bank, which passes it on to the insurer $4^{4}$ Since $\widetilde{y}=1$ with probability $q$, we have $P=q(1+$ $r) I$. Parametric insurance is imperfect, in the sense that, with probability $(1-q) f$, it fails to perform despite the farmer defaulting. Conversely, with probability $q(1-f-\varepsilon)$ the insurance contract pays out even if no loss occurs.

With this parametric insurance scheme, the incentive compatibility constraint and the bank's participation constraint are written as

$$
\begin{array}{r}
F \geq D-C, \\
\mathbb{E} \Pi^{I}=[1-(1-q) f] D+(1-q) f C-I \geq \eta .
\end{array}
$$

Figure 2 depicts the set of achievable contracts in the presence of the insurance bundling. The incentive compatibility constraint is unchanged. In contrast, the insurance contract increases the bank's profit as the low payoff $C$ is obtained with probability $f(1-q)$, which is lower than $p$, whereas the high payoff $D$ is obtained with probability $1-f(1-q)$, which is higher than $1-p$. This allows the bank to lower the collateral required and increase the loan amount without lowering its profit.

When the constraints $\left(\overline{\mathrm{IC}^{\prime}}\right)$ and $(\overline{\mathrm{PC} 1} \mathrm{~T})$ are binding, we have

$$
C_{1}^{I}=I+\eta-[1-(1-q) f] F,
$$

and $C_{1}^{I} \leq C_{1}^{N}$. Hence, under ex-post moral hazard, farmers with an asset level $A$ satisfying $C_{1}^{I}<A<C_{1}^{N}$ will receive loans under parametric insurance, whereas they would be credit rationed otherwise.

We can also compute the effect of parametric insurance on the value of nominal debt, and therefore on the interest rate. When constraints (IC1) and (PC1') are binding, we have

$$
\begin{array}{r}
D_{1}^{N}=C_{1}^{N}+F=I+\eta+p F, \\
D_{1}^{I}=C_{1}^{I}+F=I+\eta+(1-q) f F,
\end{array}
$$

with $D_{1}^{I}<D_{1}^{N}$. The cost of debt with insurance is lower than in the case without insurance, and the lowest interest rate achievable with parametric insurance is given by

$$
r_{1}^{I}=\frac{\eta+(1-q) f F}{I}<r_{1}^{N}
$$

\footnotetext{
${ }^{4}$ Farmers use resources coming from the informal sector to pay insurance premiums, without reducing the amount of collateral $A$ they can provide. It is assumed that these resources cannot be used as collateral in the absence of insurance. This might occur, for instance, when farmers have no cash available. In this case, the payment of the insurance premium can be made thanks to informal loans, made safer by the insurance scheme, granted by family relatives or acquaintances.
} 


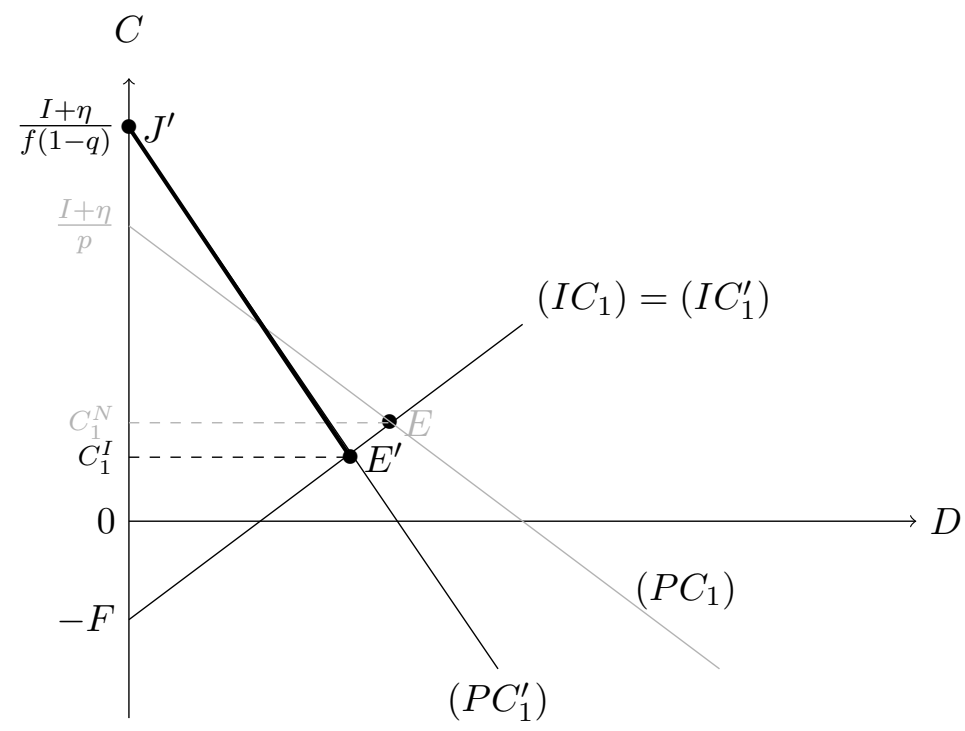

Figure 2: Ex-post moral hazard. Feasible contracts with parametric insurance. Contracts are depicted in the $(D, C)$ plane. The points on segment $\left[J^{\prime}, E^{\prime}\right]$ provide the farmer with the same level of expected income $\mathbb{E} W=N P V-\eta>0$. Inequalities ([C1)(PC1' are binding at point $E^{\prime}$, where the collateral reaches its smallest value, $C_{1}^{I}$.

The parametric insurance contract does not require the farmer's default to be verifiable by the insurer, who only observes the signal $\tilde{y}$.

The foregoing has focused attention on the case where some positive collateral is required, even when the loan contract is bundled with parametric insurance, i.e., $C_{1}^{N}>C_{1}^{I}>0$, which holds when $I+\eta>[1-(1-q) f] F$. On the contrary, we have $C_{1}^{I}<0<C_{1}^{N}$ when ${ }^{5}$

$$
(1-p) F<I+\eta<[1-(1-q) f] F .
$$

This is represented in Figure 3, where equilibrium under parametric insurance is at point $E^{\prime \prime}$, the incentive constraint $I C 1^{\prime}$ being satisfied and not binding. We have

$$
D_{1}^{I}=\frac{I+\eta}{1-(1-q) f}<D_{1}^{N}
$$

and

$$
r_{1}^{I}=\frac{\eta+(1-q) f I}{I[1-(1-q) f]}<r_{1}^{N} .
$$

\footnotetext{
${ }^{5}$ Everything else being equal, this condition holds when $(1-q) f$ is small enough, i.e., when there is a low probability that the farmer defaults and the insurance indemnity is not triggered (i.e., $\widetilde{y}=0$ and $\widetilde{R}=0$ ).
} 
In this case, farmers who cannot provide assets as collateral (i.e., those such that $A=0$ ) are granted a loan under parametric insurance, while they would be denied credit otherwise. Furthermore, as in the case with collateral requirement, parametric insurance lowers the interest rate charged on loans to farmers. This case is empirically relevant because many smallholders have no pledgeable wealth and derive most of their resources from the informal sector.

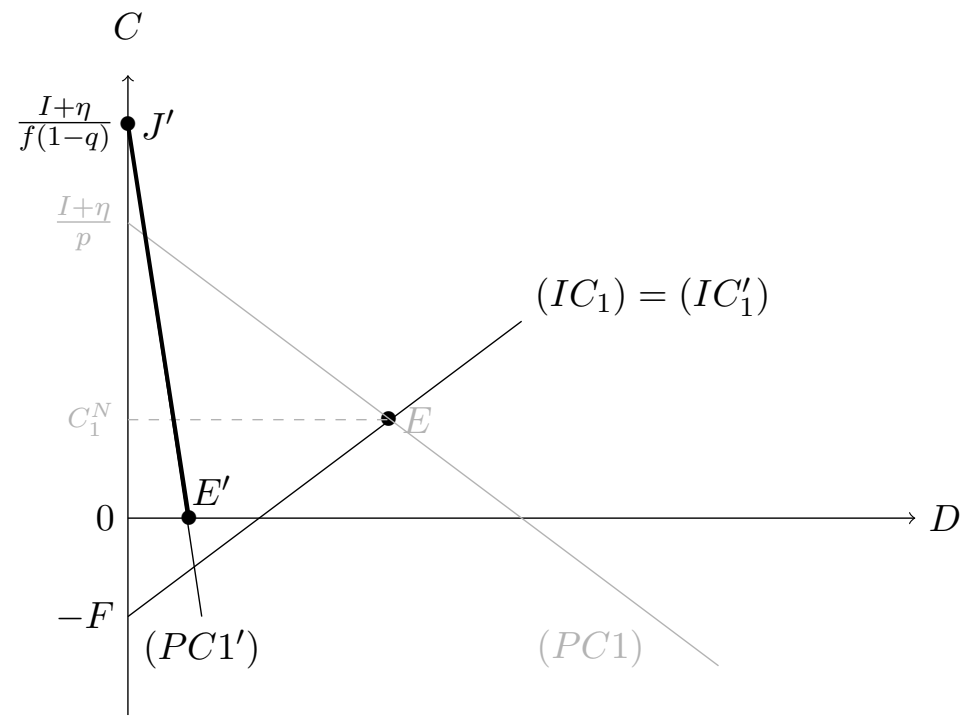

Figure 3: Ex-post moral hazard. No collateral requirement at equilibrium. Contracts are depicted in the $(D, C)$ plane. The points on segment $\left[J^{\prime}, E^{\prime}\right]$ provide the farmer with the same level of expected income $\mathbb{E} W=N P V-\eta>0$. At point $E^{\prime}$,

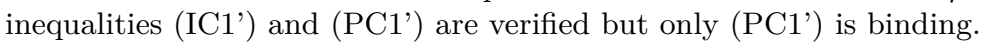

\subsection{Ex-ante moral hazard}

In this section, we let each farmer's success probability, $p(e)$, depend on the farmer's privately observable effort choice, $e \in\{b, g\}$. This effort level must be understood as a measure of the quantity and quality of actions undertaken to maximise the probability that the crop harvest is in line with the production potential associated with the target production technology. In practice, farmers may have good reasons not to pursue systematically this objective: they may share the inputs with their neighbours, or pursue several activities to diversify their income sources. Performing a low level of effort is assumed to yield a private benefit $B>0$. As in the ex-post moral hazard case, we first consider the case without insurance. After funds of amount $I$ have been provided by the bank, the farmer's cash-flow is $R>0$ with probability $1-p(e)$ and 0 with probability $p(e)$. This means, in particular, 
that both the exogenous (weather) shock and the farmer's effort shape the distribution of the project's terminal payoff.

The joint effect of farmer's effort and weather risk is modelled by writing the conditional probability of loan default as follows:

$$
\begin{aligned}
& \mathbb{P}(\tilde{R}=0 \mid \tilde{y}=1, e)=f(e)+\varepsilon \\
& \mathbb{P}(\tilde{R}=0 \mid \tilde{y}=0, e)=f(e),
\end{aligned}
$$

with $\tilde{R}$ denoting the random project's outcome, and where we assume $\varepsilon>0$, $0<f(g)<f(b)$, and $f(b)+\varepsilon<1$. In words, for any effort level $e \in\{b, g\}$, the occurrence of the weather shock increases the probability of failure by $\varepsilon$. On the other hand, for any weather shock realization, the effort level $\{e=g\}$ reduces the default probability by $f(b)-f(g)$.

We set $f(g) \equiv f_{g}$ and $f(b)=f_{b}$, with $f_{b}>f_{g}$. We denote by $p_{g}=f_{g}+q \varepsilon$ and $p_{b}=f_{b}+q \varepsilon$ the probabilities that a weather shock occurs when the farmer uses credit productively or not, respectively. Table 1 is accordingly modified by replacing $f$ and $p$ by $f_{g}$ and $p_{g}$ when $e=g$, and by $f_{b}$ and $p_{b}$ when $e=b$.

We now introduce the ex-ante moral hazard counterparts of Hypotheses $\mathrm{H} 1, \mathrm{H} 2$ and $\mathrm{H} 3$.

$$
\begin{array}{r}
N P V=\left(1-p_{g}\right) R-I \geq \eta, \\
R \geq \frac{B}{\Delta_{p}} \\
I+\eta>\left(1-p_{g}\right)\left(R-\frac{B}{\Delta_{p}}\right),
\end{array}
$$

with $\Delta_{p}=p_{b}-p_{g}>0$. By Hypothesis (H4) above, when the farmer exerts high effort the project has an $N P V$ larger than the reservation profit of the bank. Hypothesis (H5) means that the farmer's income in the successful state is large enough to provide incentives to the farmer. As will be shown below, Hypothesis (H6) requires a positive level of collateral to incentivize the farmer to provide the right level of effort.

\section{Case without insurance}

Without insurance, the only possibility for the bank to reduce the risk of loan non-repayment is to require the posting of a collateral in amount $C$. The incentive compatibility constraint of the farmer and the participation constraint of the bank are now written as

$$
\begin{array}{r}
R+C-D \geq \frac{B}{\Delta_{p}}, \\
\left(1-p_{g}\right) D+p_{g} C-I \geq \eta,
\end{array}
$$


respectively ${ }^{6}$ Notice that, when the participation constraint of the bank is binding, the expected value of the farmer's final wealth $W$ is given by

$$
\mathbb{E} W=\left(1-p_{g}\right)(R-D)-p_{g} C=N P V-\eta \geq 0 .
$$

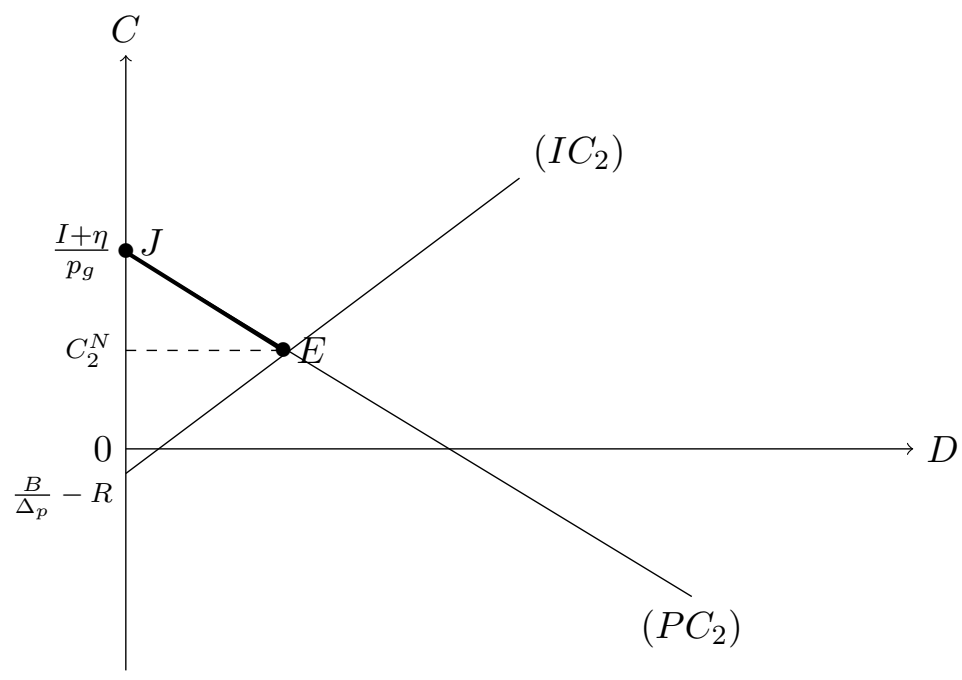

Figure 4: Ex-ante moral hazard. Feasible contracts without insurance. Contracts are depicted in the $(D, C)$ plane. Inequalities $(\mathrm{IC} 2)-(\mathrm{PC} 2)$ are binding at point $E$, where the collateral reaches its smallest value, $C_{2}^{N}$.

Figure 4 illustrates the set of contracts satisfying the incentive compatibility and participation constraints. From the viewpoint of the farmer, the set of optimal contracts, that is the ones yielding $\mathbb{E} W=N P V-\eta$, is represented on the segment $[J, E]$. When constraints $(I C 2)$ and $(P C 2)$ are binding, we can solve for the lowest amount of collateral required in the case of no insurance:

$$
C_{2}^{N}=I+\eta-\left(1-p_{g}\right)\left(R-\frac{B}{\Delta_{p}}\right)
$$

with $C_{2}^{N}>0$ from $(\mathrm{H} 6)$.

\section{Case with parametric insurance}

We now consider the case in which parametric insurance is available. As in the ex-post moral hazard case, insurance pays the amount $D$ to the lender when $\tilde{y}=1$, thus exempting the farmer from repaying the loan. The insurance contract pays nothing when $\tilde{y}=0$. The loan contract stipulates that

\footnotetext{
${ }^{6}$ The farmer is incentivized to choose $e=g$ rather than $e=b$ if $\left(1-p_{g}\right)(R-D)-p_{g} C \geq$ $\left(1-p_{b}\right)(R-D)-p_{b} C+B$, which gives $(\mathrm{IC} 2)$.
} 
the farmer receives the collateral back when the loan is repaid, either by the farmer, when $\widetilde{R}=R$ and $\widetilde{y}=0$, or by the insurer, when $\widetilde{y}=1$ (and $\widetilde{R}=0$ or $R$ ).

The insurance premium paid by the farmer is actuarially fair, which gives $P=q(1+r) I$. We will see that this is equivalent to farmers paying the insurance premium in the form of a spread added to the borrowing rate. As in the ex-post moral hazard case, parametric insurance is imperfect, in the sense that, with probability $(1-q) f(e)$, it fails to perform when the farmer defaults. Conversely, with probability $q(1-f(e)-\varepsilon)$ the insurance contract pays out while no loss occurs. The case $\varepsilon=1$ and $f=0$ represents a perfect index, in which a payout is made if and only if the farmer defaults.

The incentive compatibility and participation constraints are written as

$$
\begin{array}{r}
R+(C-D)(1-q) \geq \frac{B}{\Delta_{p}} \\
{\left[1-(1-q) f_{g}\right] D+(1-q) f_{g} C-I \geq \eta .}
\end{array}
$$

When $(\overline{\mathrm{PC} 2} \mathrm{~T})$ is binding, we obtain again that

$$
\mathbb{E} W=N P V-\eta \geq 0,
$$

so that the farmer's expected final wealth is non-negative, and equal to the $N P V$ of the project minus the required profit of the bank.

Figure 5 illustrates the set of contracts that satisfy both the incentive compatibility and participation constraints when parametric insurance is available. From the standpoint of the farmer, the set of optimal contracts are now represented on segment $\left[J^{\prime}, E^{\prime}\right]$. Constraints $\left(\overline{\mathrm{IC}} 2^{\prime}\right)$ and $\left(\overline{\mathrm{PC}} 2^{\prime}\right)$ written as equalities provide the smallest feasible collateral,

$$
C_{2}^{I}=I+\eta-\frac{1-(1-q) f_{g}}{1-q}\left(R-\frac{B}{\Delta_{p}}\right)
$$

where we note that $C_{2}^{I}>0$ if

$$
I+\eta>\left[1-(1-q) f_{g}\right] /(1-q)\left(R-B / \Delta_{p}\right),
$$

and that we have $C_{2}^{I}<C_{2}^{N}$. Once again, the smallest collateral achievable under parametric insurance is lower than without insurance. Thus, farmers with assets $A$ satisfying $C_{1}^{I}<A<C_{1}^{N}$ will avoid credit rationing and receive loans thanks to parametric insurance.

We have $C_{2}^{I}<0<C_{2}^{N}$ when (4) does not hold. This case is represented in Figure 6 with equilibrium point $E^{\prime}$ at $C=0$. In this case, farmers who cannot provide assets as collateral are granted a loan under parametric insurance, while they would be denied credit otherwise. 


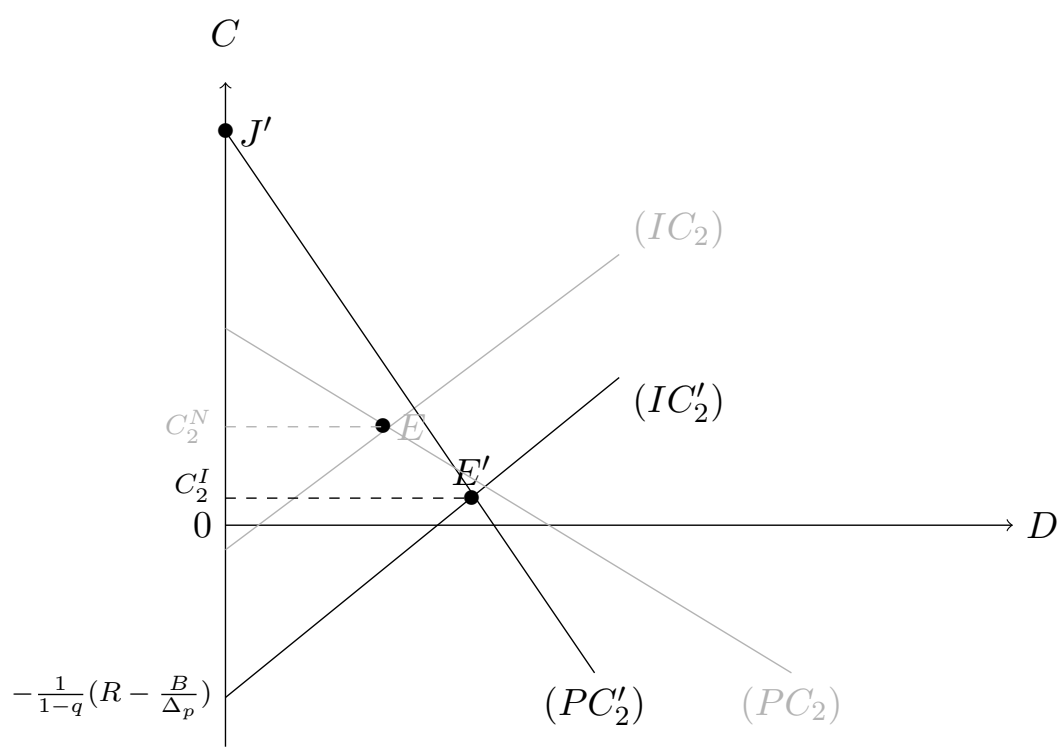

Figure 5: Ex-ante moral hazard. Feasible contracts with parametric insurance. From the standpoint of the farmer, the set of optimal contracts is now represented by the segment $\left[J^{\prime}, E^{\prime}\right]$. Constraints $(\overline{\mathrm{IC}} 2)-\left(\overline{\mathrm{PC}} 2^{\prime}\right)$ are binding at point $E^{\prime}$, where the collateral reaches its smallest value, $C_{2}^{I}$.

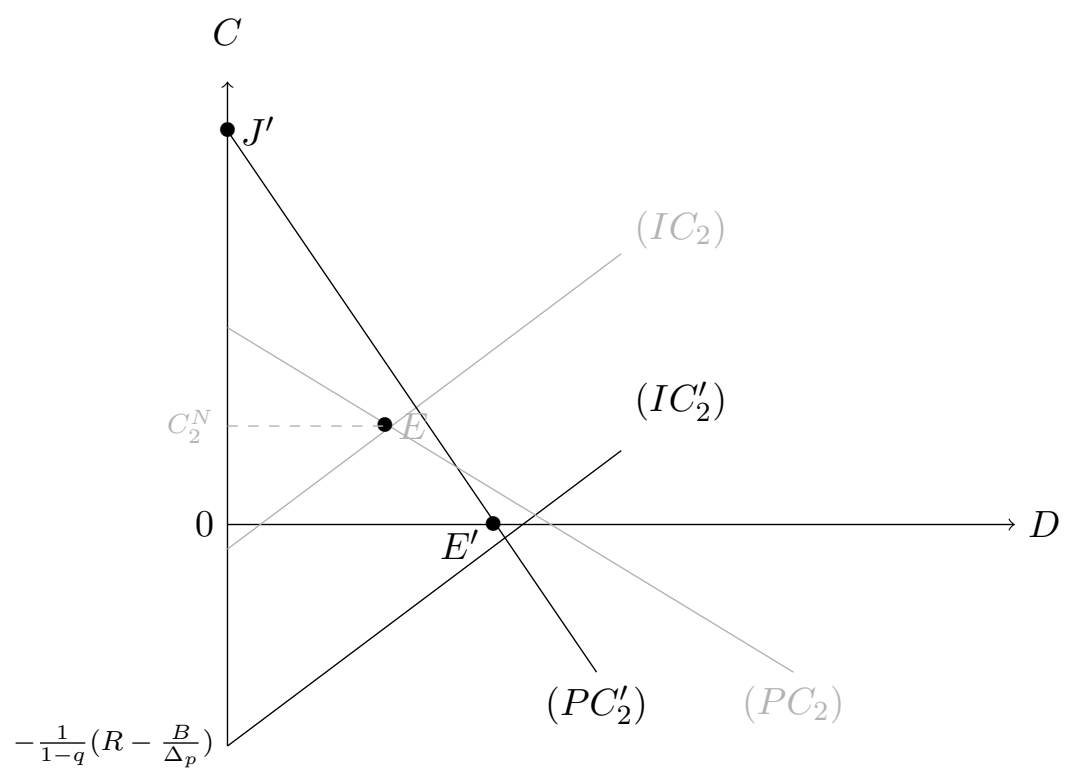

Figure 6: Ex-ante moral hazard, with parametric insurance and no collateral requirement at equilibrium. From the standpoint of the farmer, the set of optimal contracts is represented by the segment $\left[J^{\prime}, E^{\prime}\right]$. At $E^{\prime}$ only inequality $(\overline{\mathrm{PC} 2})$ binds. 


\section{Interpretation - collateral size}

Parametric insurance has two effects in the ex-ante moral hazard model. First, providing insurance relaxes the incentive compatibility constraint of the farmer. This can be seen by noting that the constraint moves from $C \geq D-\left(R-B / \Delta_{p}\right)$ to $C \geq\left[D-\left(R-B / \Delta_{p}\right)\right] /(1-q)$. Indeed, insurance lowers the liability of the farmer in the state of nature where she is able to repay her loan (i.e., when $\tilde{y}=1$ and $\tilde{R}=R$ ). The retained share of $\tilde{R}$ increases, thus strengthening the incentive to choose the high effort level. This effect leads to a reduction in $C$ for given $D$, which is illustrated in Figures 5 and 6 by the downward shift from line $(I C 2)$ to line $\left(I C 2^{\prime}\right)$. This is an important result that stands in contrast to the common shirking effect of insurance under moral hazard: parametric insurance bundled with a loan contract does instead incentivize the farmer to exert effort, as the share of output is increased in case of success.

The second effect of the introduction of parametric insurance is that the expected cost for the bank is decreased for any given behaviour of the farmer. Indeed, the bank receives $D$ with a higher probability $1-(1-q) f_{g}>1-p_{g}$ since it receives the indemnity from the insurer when the index takes a value of 1 .

Using the incentive constraints $\mathrm{IC} 2$ and $(\mathrm{IC} 2)$ and the values of $C_{2}^{N}$ and $C_{2}^{I}$, we obtain

$$
\begin{gathered}
D_{2}^{N}=I+\eta+p_{g}\left(R-\frac{B}{\Delta_{p}}\right), \\
D_{2}^{I}=I+\eta+f_{g}\left(R-\frac{B}{\Delta_{p}}\right) .
\end{gathered}
$$

As $p_{g}=f_{g}+q \varepsilon$, we have $D_{2}^{N}>D_{2}^{I}$ for any $\varepsilon>0$, and hence $r_{2}^{N}>r_{2}^{I}$. As in the ex-post moral hazard case, the parametric insurance contract therefore lowers the interest rate required by the bank.

\subsection{Combination of ex-post and ex-ante moral hazard}

We have considered so far ex-post and ex-ante moral hazard separately, and the question naturally arises of how these two forms of moral hazard interact when they coexist. In the present model, the answer is rather simple. The insurer's participation constraint is the same in both cases: (PC2) is identical to (PC1) when $p=p_{g}$, and (PC2') is identical to (PC1') when $f=f_{g}$. Furthermore, the incentive constraints (with and without parametric insurance) require that the difference $D-C$ is upper bounded. Hence, if the two forms of moral hazard have to be deterred simultaneously, $D-C$ should be limited by the minimum of these two upper bounds. This is written as 


$$
\begin{array}{r}
D-C \leq \min \left\{F, R-\frac{B}{\Delta_{p}}\right\}, \\
D-C \leq \min \left\{F, \frac{1}{1-q}\left(R-\frac{B}{\Delta_{p}}\right)\right\},
\end{array}
$$

where $(\overline{\mathrm{IC} 12})$ and $(\overline{\mathrm{IC} 12})$ are these new incentive compatibility constraints, without and with parametric insurance, respectively.

Let $C_{12}^{N}$ and $C_{12}^{I}$ denote the minimum collateral under simultaneous expost and ex-ante moral hazard, without insurance and with parametric insurance, respectively, and let

$$
\begin{aligned}
\Delta C_{1} & =C_{1}^{N}-C_{1}^{I}, \\
\Delta C_{2} & =C_{2}^{N}-C_{2}^{I}, \\
\Delta C_{12} & =C_{12}^{N}-C_{12}^{I},
\end{aligned}
$$

be the decrease in collateral made possible by parametric insurance, under ex-post moral hazard, ex-ante moral hazard, and a mixture of both, respectively. One easily checks that $C_{12}^{N}=\max \left\{C_{1}^{N}, C_{2}^{N}\right\}$ and $C_{12}^{I}=$ $\max \left\{C_{1}^{I}, C_{2}^{I}\right\}$, which gives

$$
\Delta C_{12}=\max \left\{C_{1}^{N}, C_{2}^{N}\right\}-\max \left\{C_{1}^{I}, C_{2}^{I}\right\} .
$$

Simple calculations allow us to deduce $e^{7}$

$$
\max \left\{\Delta C_{1}, \Delta C_{2}\right\} \geq \Delta C_{12} \geq \min \left\{\Delta C_{1}, \Delta C_{2}\right\}
$$

In the present model, parametric insurance allows the bank to reduce the minimum collateral by amount $\Delta C_{1}$ or $\Delta C_{2}$ according to the origin of moral hazard, i.e., depending on whether it is ex-post or ex-ante. When it comes to deter both types of misbehaviour simultaneously, the feasible decrease in collateral $\Delta C_{12}$ is bounded by the minimum and maximum possible decrease for each type of misbehaviour independently of the other. In particular, we have $\Delta C_{12}<\Delta C_{1}+\Delta C_{2}$, which means that collateral decreases are not cumulative. Figure 7 illustrates the case where $C_{12}^{N}=C_{2}^{N}$ and $C_{12}^{I}=C_{1}^{I}$, with $\Delta C_{1}<\Delta C_{12}<\Delta C_{2}$.

\footnotetext{
${ }^{7}$ When $C_{1}^{I} \leq C_{2}^{I}$, we have $\Delta C_{12}=\max \left\{C_{1}^{N}-C_{2}^{I}, \Delta C_{2}\right\} \geq \Delta C_{2}$ and thus $\Delta C_{12} \geq$ $\min \left\{\Delta C_{1}, \Delta C_{2}\right\}$. Similarly, when $C_{2}^{I} \leq C_{1}^{I}$, we have $\Delta C_{12}=\max \left\{\Delta C_{1}, C_{2}^{N}-C_{1}^{I}\right\} \geq$ $\Delta C_{1}$ and thus $\Delta C_{12} \geq \min \left\{\Delta C_{1}, \Delta C_{2}\right\}$ also holds in that case. When $C_{1}^{N} \leq C_{2}^{N}$, we have $\Delta C_{12}=\min \left\{C_{2}^{N}-C_{1}^{I}, \Delta C_{2}\right\} \leq \Delta C_{2}$, and thus $\Delta C_{12} \leq \max \left\{\Delta C_{1}, \Delta C_{2}\right\}$. Finally, when $C_{2}^{N} \leq C_{1}^{N}$, we have $\Delta C_{12}=\min \left\{\Delta C_{1}, C_{1}^{N}-C_{2}^{I}\right\} \leq \Delta C_{1}$, and thus, we also have $\Delta C_{12} \leq \max \left\{\Delta C_{1}, \Delta C_{2}\right\}$ in that case.
} 


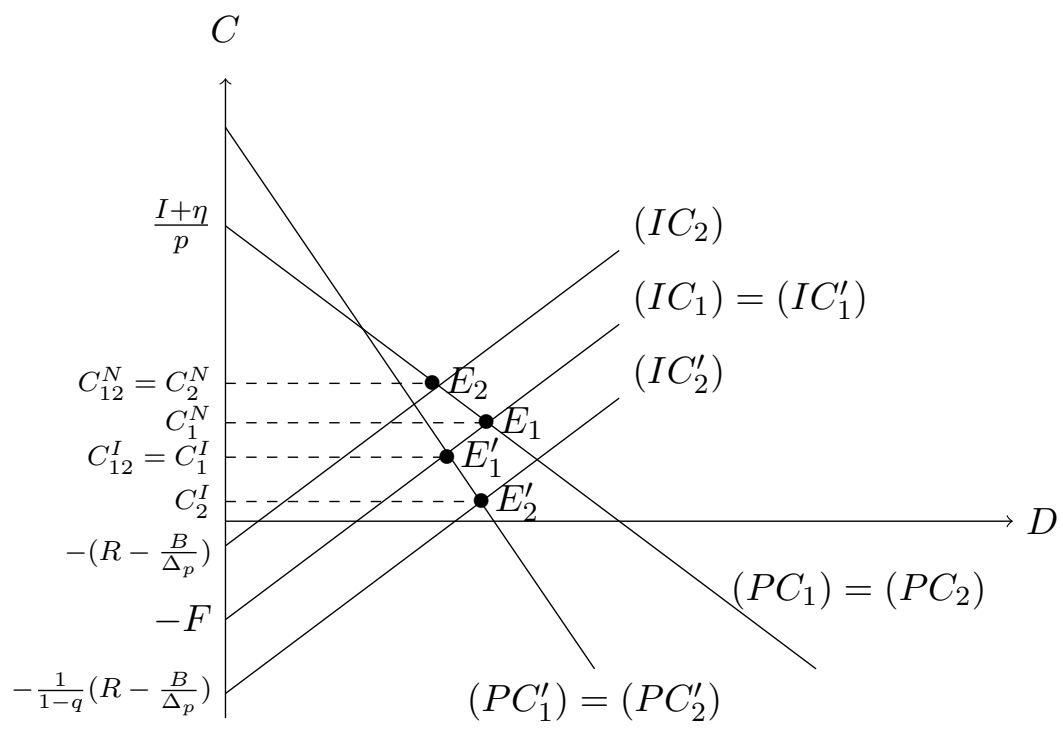

Figure 7: Combination of ex-post and ex-ante moral hazard. Case where $\Delta C_{1}<\Delta C_{12}<\Delta C_{2}$.

\subsection{Features of the optimal insurance contract}

\subsubsection{Should the insurance payment go to the bank or to the farmer?}

We have assumed that the insurance payouts go directly to the bank. However, the question of whether this money should be directed to the borrower rather than the lender is a subject of debates between development economists and practitioners. Some argue that channelling the payouts through farmers involves the risk of diverting the insurance compensation from its primary function of securing the repayment of loans, while others emphasise that this would allow farmers to smooth their consumption over time, in response to fluctuations in income. Although an analysis of farmers' inter-temporal choices is beyond the scope of the present paper, we may nevertheless have a first look at this issue within our model.

Assume that the parametric insurance coverage is mandatory in order to be eligible for a loan, and that the insurance payout $D$ is allocated to the farmer when $\widetilde{y}=1$. The farmer, in turn, shall pay $D$ to the bank when $\widetilde{R}=R$ and/or $\widetilde{y}=1$. It is further assumed that the bank observes signal $\widetilde{y}$. Diverting the insurance payout when $\widetilde{y}=1$ provides a net gain $D-C$ to the farmer. The latter refrains from such dishonest behaviour if

$$
F^{\prime} \geq D-C
$$

where $F^{\prime}$ denotes the costs incurred by the farmer who diverts the insurance 
payout, including the impossibility to be granted another loan in the future and possible fines if she is found guilty of embezzling insurance funds. Incentive constraint (IC3) should be added to (IC1') and ( and ( $\left(\mathrm{PC}^{2}\right)$ under ex-post and ex-ante moral hazard, respectively.

In the ex-post moral hazard case, it is likely that diverting insurance coverage without being able to hide this behaviour, entails larger costs than pretending to be in default. Hence, it seems reasonable to presume that $F^{\prime}$ is larger than $F$, and thus that (IC3) is implied by (IC1). In other words, in the ex-post moral hazard case, preventing the farmer from diverting insurance coverage does not require an additional incentive constraint, and our conclusions remain unchanged, irrespective of whether insurance money is channelled through the farmer, or is directly paid to the bank.

Matters are different in the ex-ante moral hazard case. In this case, the necessity to prevent the farmer from unduly retaining the insurance payment gives rise to an additional incentive constraint due to ex-post moral hazard. We are therefore in the case where two types of moral hazard coexist. This may reduce the drop in collateral made possible by insurance. This is illustrated in Figure 8, where $C_{2}^{I}$ and $C_{3}^{I}$ are the minimum collateral amounts when the insurance payout is delivered to the bank and to the farmer, respectively, with $C_{2}^{I}<C_{3}^{I}$. All in all, this suggests that a reason exists for channelling the insurance payout directly to the bank, although it must be acknowledged that the income smoothing motive has been ignored, which could tip the balance in favour of the other solution.

\subsubsection{Subsidisation and loading of parametric insurance}

When the bank makes no profit, the effect of a loan on welfare can be measured by the $N P V$ of the financed project since the absence of collateral is the unique barrier to credit access. Therefore, if $G$ is the cumulative distribution function of the pledgeable wealth $A$ across the population, parametric insurance improves (average) welfare by a quantity $\left[G\left(C_{1}^{N}\right)-G\left(C_{1}^{I}\right)\right] \times N P V$ or $\left[G\left(C_{2}^{N}\right)-G\left(C_{2}^{I}\right)\right] \times N P V$ in the ex-post and ex-ante moral hazard cases, respectively 8

We have assumed so far that the insurance premium is paid by farmers out of resources from informal activity. These resources are not verifiable, and thus they cannot be included in the collateral required by the bank, but they can be used to pay the insurance premium. The payment of insurance

\footnotetext{
${ }^{8}$ We assume here that farmers hold enough resources from the informal sector to pay the insurance premium. See below for a more general case where this assumption may fail.

${ }^{9}$ The risk-neutrality assumption allows us to identify the welfare gain of a loan to the project's NPV. Since parametric insurance provides partial coverage, taking into account the farmer's risk aversion would reduce the welfare gain of loans. See Clarke (2016) for an analysis of the relationship between risk aversion and the demand for insurance.
} 


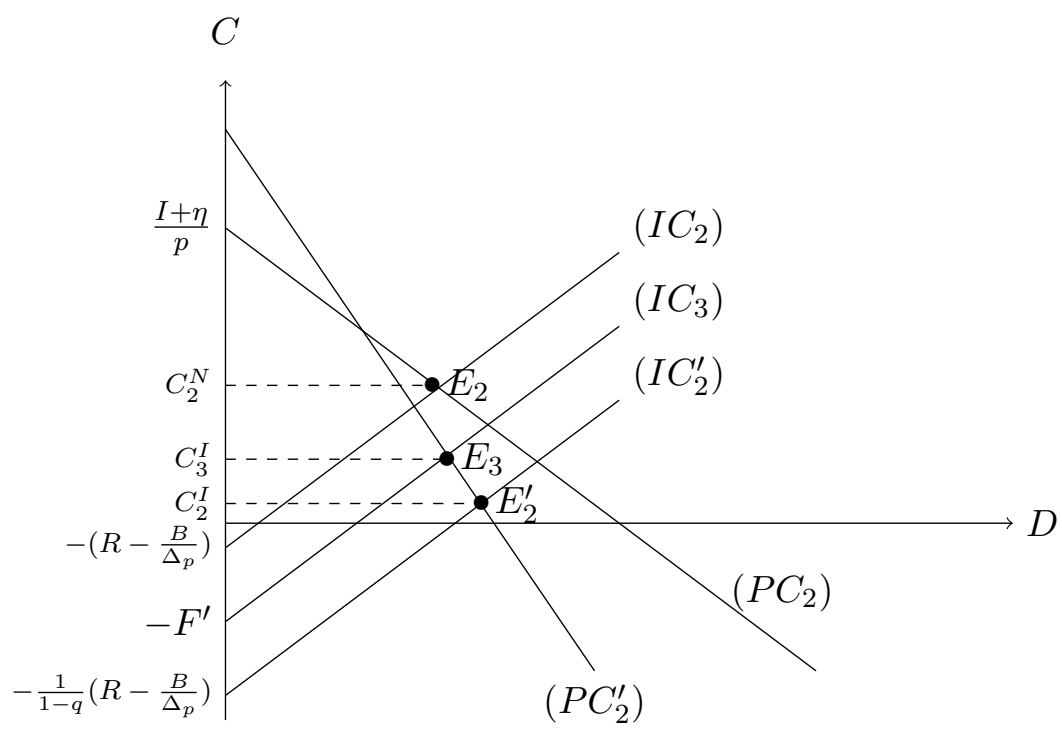

Figure 8: Feasible contracts with parametric insurance when the insurance payment goes to the farmer. The new constraint $[\mathrm{IC} 3$, induced by the possibility of insurance embezzlement, may reduce the drop in collateral created by parametric insurance. If constraint (IC3) binds, the equilibrium collateral is higher when the payment goes to the farmer $\left(C_{3}^{I}>C_{2}^{I}\right)$.

premium is thus a way of transferring resources from the informal sector to the formal sector.

We have also assumed that insurance was actuarially fairly priced, and that farmers can afford this payment, with positive expected profit $\mathbb{E} W=$ $N P V-\eta>0$ from the new technology. Therefore in the foregoing, the condition on collateral was the only constraint faced by loan applicants. However, in practice, farmers have limited resources from the informal sector, which may prevent them from paying the insurance premium, especially since insurance premiums are loaded due to transaction costs. This resource availability constraint is relaxed if insurance is subsidised by the government. Since obtaining a loan allows the farmer to create value by an amount equal to the $N P V$, subsidising insurance may be welfare improving if the social costs of such subsidies are not prohibitive.

In order to explore this issue, let us assume that each farmer is characterized by the maximum insurance premium $\omega$ she can afford. Assume also that insurance premium $P$ is equal to the actuarially fair premium $q D$ loaded at rate $\sigma$ by insurers, and subsidized at rate $\tau$ through government funding, hence with $P=(1+\sigma-\tau) q D$. A type- $\omega$ farmer is able to pay the premium if $\omega \geq P$. For simplicity, assume that $\omega$ and available collateral $A$ are independently distributed in the population of farmers, and let $H(\omega)$ and $G(A)$ be the c.d.f. of $\omega$ and $A$, respectively. Let us measure the contri- 
bution of a loan to aggregate social welfare by the difference between its net present value $N P V$ and the cost of public funds used for insurance subsidization, i.e., $N P V-\lambda \tau q D$, where $\lambda$ is the social cost of public funds ${ }^{10} \mathrm{In}$ the case of ex-post moral hazard, the contribution of loans to social welfare (per farmer in the population) is written as

$$
W(\tau)=\left[1-G\left(C_{1}^{I}\right)\right]\left[1-H\left((1+\sigma-\tau) q D_{1}^{I}\right)\right]\left(N P V-\lambda \tau q D_{1}^{I}\right),
$$

where $1-G\left(C_{1}^{I}\right)$ and $1-H\left((1+\sigma-\tau) q D_{1}^{I}\right)$ are the proportions of farmers with enough collateral and enough resources from informal activity to afford parametric insurance. An increase in $\tau$ and a decrease in $\sigma$ would make insurance more affordable, and would increase the proportion of farmers who apply for a loan. We deduce

$$
W^{\prime}(0)=\left[1-G\left(C_{1}^{I}\right)\right] q D_{1}^{I}\left\{h\left((1+\sigma) q D_{1}^{I}\right) N P V-\lambda\left[1-H\left((1+\sigma) q D_{1}^{I}\right)\right]\right\},
$$

where $h(\omega)=H^{\prime}(\omega)$, and thus $W^{\prime}(0)>0$ if

$$
\lambda<N P V \frac{h\left((1+\sigma) q D_{1}^{I}\right)}{1-H\left((1+\sigma) q D_{1}^{I}\right)},
$$

This confirms that some degree of insurance subsidisation is welfare improving if the cost of public funds is not too large. Replacing $D_{1}^{I}$ by $D_{2}^{I}$ provides a similar condition in the case of ex-ante moral hazard. Interestingly, the right-hand-side of (6) is increasing in $\sigma$ when the hazard rate $h(\omega) /[1-H(\omega)]$ is increasing, a condition satisfied by most usual probability distributions. Since $D_{1}^{I}$ and $D_{2}^{I}$ do not depend on $\sigma$, this suggests that insurance subsidisation is more desirable when insurers charge expensive premiums.

Subsidisation and loading also affect technology adoption through their effects on the farmer's expected profit. When $P=(1+\sigma-\tau) q D$, we have

$$
\mathbb{E} W=N P V-\eta-(\sigma-\tau) q D .
$$

As can be expected, the higher the loading factor, the lower the farmer's expected profit, while the subsidy rate works in reverse. Making technology adoption attractive may thus require that insurance is subsidised when transaction costs are reflected by a large loading factor.

\subsubsection{Basis risk}

We may measure the basis risk by the probability $\alpha$ that there is no insurance payout, although the farmer's project fails, i.e.

$$
\alpha=\operatorname{Pr}(\widetilde{y}=0, \widetilde{R}=0)=f(1-q),
$$

\footnotetext{
${ }^{10} \mathrm{As}$ abundantly motivated in the public finance literature, the cost of public funds results from the economic distortions generated by taxation.
} 
which depends on parameters $f$ and $q$, with $\varepsilon$ such that $p=f+q \varepsilon$. Hence, for $p$ given, a higher $f$ and a lower $q$, with $\varepsilon=(p-f) / q$, both increase basis risk.

In the case of ex-post moral hazard, the parametric insurance cover does not affect the incentive to tell the truth (constraints (IC1) and (IC1) coincide) and its effect on the minimum required collateral goes through the bank's participation constraint $(\overline{\mathrm{PC} 1}])$. This constraint may be rewritten as

$$
(1-\alpha) D+\alpha C \geq I+\eta .
$$

We have $D>C$ when $(\overline{I C 1})$ is binding, and an increase in $\alpha$ makes the bank's participation constraint more restrictive, which ultimately increases the required collateral

$$
C_{1}^{I}=I+\eta-(1-\alpha) F .
$$

In brief, in the case of ex-post moral hazard, a smaller basis risk does not modify the farmer's truth-telling condition. It just allows the bank to be more completely covered by insurance, and consequently to require a lower collateral.

Things are different in the case of ex-ante moral hazard. On the one hand, as in the ex-post moral hazard case, the bank's participation constraint may still be written as (7), with $\alpha=f_{g}(1-q)$, and an increase in $\alpha$ makes this constraint more restrictive when $C<D$. On the other hand, parametric insurance affects farmers' incentives through two channels. Firstly, the farmer does not lose her collateral $C$ when $\widetilde{R}=0$ and $\widetilde{y}=1$, while she would lose it in the absence of insurance. This first effect decreases the farmer's incentive to choose $e=g$, since it corresponds to a protection in the case of failure. Secondly, when $\widetilde{R}=R$ and $\widetilde{y}=1$, the insurer replaces the farmer and pays $D$ to the bank, which is an incentive to choose $e=g$, since the expected gain of the farmer in case of success is increased. When $C<D$, the incentive effect of the reward $D$ in case of success is larger than the disincentive of not losing $C$ in case of failure, and consequently parametric insurance exerts a favorable effect on farmer's incentives. As shown by constraint (IC2), this incentive effect depends on $q$. We may isolate the effect of the background risk on the bank's profit that depends on $\alpha$ from this incentive effect that depends on $q$, by writing

$$
C_{2}^{I}=I+\eta-\frac{1-\alpha}{1-q}\left(R-\frac{B}{\Delta_{p}}\right) .
$$

In sum, in both cases a lower basis risk $\alpha$ reduces the required collateral. In the case of ex-ante moral hazard, this effect is exacerbated by an increase in farmers' incentives if the decrease in $\alpha$ comes from an increase in $q$. 


\subsubsection{Perception of basis risk}

Farmers may perceive that the insurance coverage is affected by a large basis risk, and thus that they are at risk of losing their collateral with a high probability if their investment fails, either because they anticipate that there is a risk of contract nonperformance (meaning that payout $D$ might not be allocated by the insurer to the bank when $\widetilde{y}=1$ ) or because farmers undervalue the probability that $\widetilde{y}=1$. Following Doherty and Schlesinger (1991), contract nonperformance has been identified as a reason for which individuals may be reluctant to purchase insurance, and Peter and Ying (2019) have identified conditions under which this effect is exacerbated by policyholders' ambiguity aversion. From this perspective, as highlighted by Bryan (2019), ambiguity-averse farmers who face new technologies with uncertain return, may be reluctant to purchase parametric insurance, if they anticipate that the insurance payout will not be delivered as expected. It is hence worth investigating how our conclusions are modified, when farmers perceive a risk of contract nonperformance, and when the probability distribution of index $\widetilde{y}$ is imperfectly known to them and they are ambiguity-averse.

Let us first consider the risk of contract nonperformance. Assume that farmers anticipate that insurance coverage is triggered with probability $\theta$ lower than one, when $\widetilde{y}=1$. In words, they do not have full confidence in the insurance mechanism, and they fear that the insurer may deny coverage improperly. We assume that this simply reflects farmers' lack of trust, and not the actual implementation of the insurance contract.11

Under ex-post moral hazard, incentive compatibility takes the form of truth-telling condition (IC1'), which is not affected by farmers' lack of trust. The bank's participation constraint $(\overline{\mathrm{PC} 1})$ is not modified, because the contract nonperformance risk only reflects a perception bias of farmers. Consequently, the minimum required collateral $C_{1}^{I}$ remains unchanged. When insurance is sold at actuarially fair price, the expected income of farmers is equal to the net present value of the project minus the bank's reservation profit, i.e., $\mathbb{E} W=N P V-\eta$. However, farmers perceive a lower expected income $\mathbb{E} W^{p}$ given by

$$
\mathbb{E} W^{p}=\mathbb{E} W-(1-\theta)\left[D_{1}^{I} \operatorname{Pr}(\widetilde{R}=R, \widetilde{y}=1)+C_{1}^{I} \operatorname{Pr}(\widetilde{R}=0, \widetilde{y}=1)\right],
$$

because they anticipate that they may have to reimburse the loan or to lose the collateral when the insurer improperly denies coverage. When $C_{1}^{I}>0$, this gives

$$
\mathbb{E} W^{p}=\mathbb{E} W-q(1-\theta)[I+\eta-F(q f+\varepsilon)],
$$

\footnotetext{
${ }^{11}$ In other words, the insurance coverage is triggered when $\widetilde{y}=1$, and banks know it. However, farmers fear that this might not always be the case, and that such a contract nonperformance would work against them. The case where the insurance indemnity is actually paid with probability $(1-\theta) q$ would be tantamount to replacing $q$ by $(1-\theta) q$, and in that case the contract nonperformance would have the same effect as a decrease in probability $q$.
} 
and

$$
I+\eta-F(q f+\varepsilon)>(I+\eta) \frac{1-f-\varepsilon}{1-(1-q) f}>0,
$$

which yields

$$
\mathbb{E} W^{p}<\mathbb{E} W-q(1-\theta)(I+\eta) \frac{1-f-\varepsilon}{1-(1-q) f} .
$$

Thus, we may have simultaneously $\mathbb{E} W>0$ and $\mathbb{E} W^{p}<0$ when $\theta$ is small, i.e., when farmers have a low degree of trust in the insurance cover 12 In such a case, farmers would prefer not to apply for a loan rather than being exposed to the risk of contract nonperformance.

Under ex-ante moral hazard, the farmer's lack of trust affects the incentive compatibility constraint: $q$ should be replaced by $\theta q$ in (IC2'), which gives

$$
R+(C-D)(1-\theta q) \geq \frac{B}{\Delta_{p}},
$$

while the insurer's participation constraint $\left(\mathrm{PC}^{2}\right)$ is unchanged. Using (IC2") and $(\overline{\mathrm{PC} 2})$ as equalities gives

$$
\begin{aligned}
& C_{2}^{I}=I+\eta-\frac{1-(1-q) f_{g}}{1-\theta q}\left(R-\frac{B}{\Delta_{p}}\right), \\
& D_{2}^{I}=I+\eta+\frac{(1-q) f_{g}}{1-\theta q}\left(R-\frac{B}{\Delta_{p}}\right) .
\end{aligned}
$$

when $C_{2}^{I}>0$. Hence, the lower $\theta$, i.e., the lower the trust in the insurance mechanism, the higher the required collateral. This effect of trust on the required collateral goes through the farmers' incentives, and it can be intuitively interpreted as follows. When $\theta$ decreases, farmers anticipate that they will reimburse the loan and lose the collateral more frequently, with disincentive and incentive effects, respectively. We have $C<D$ when (IC2") is binding, and thus globally a decrease in $\theta$ reduces the farmers' incentives, which should be compensated by an increase in the collateral.

Furthermore, we may write the expected income perceived by the farmer as

$$
\mathbb{E} W^{p}=\mathbb{E} W-(1-\theta)\left[D_{2}^{I} \operatorname{Pr}(\widetilde{R}=R, \widetilde{y}=1)+C_{2}^{I} \operatorname{Pr}(\widetilde{R}=0, \widetilde{y}=1)\right],
$$

which gives

$$
\begin{aligned}
\mathbb{E} W^{p} & =\mathbb{E} W-q(1-\theta)\left[I+\eta-\frac{q f_{g}+\varepsilon}{1-\theta q}\left(R-\frac{B}{\Delta_{p}}\right)\right] \\
& <\mathbb{E} W-q(1-\theta)(I+\eta) \frac{1-f_{g}-\varepsilon}{1-(1-q) f_{g}},
\end{aligned}
$$

\footnotetext{
${ }^{12} \mathrm{~A}$ similar conclusion is obtained when $C_{1}^{I}=0$.
} 
when $C_{2}^{I}>0$. Thus, as in the ex-post moral hazard case, we may have simultaneously $\mathbb{E} W>0$ and $\mathbb{E} W^{p}<0$ when $\theta$ is small, with the same consequence of the lack of trust in the insurance cover.

Let us look now at the case in which ambiguity-averse farmers have imperfect information about the probability distribution of the index $\widetilde{y}$, while banks know the true probability $q$. Following Gilboa and Schmeidler (1989), we may assume that farmers have maxmin preferences: their set of possible beliefs about $q$ includes all probability distributions over a compact set $[\underline{q}, \bar{q}] \subset[0,1]$ that includes the true probability $q$. Farmers behave by considering the worst-case scenario, i.e., $q=\underline{q}$. This corresponds to the case where the parametric insurance cover is triggered with the lowest probability among admissible beliefs, which is formally equivalent to the case of contract nonperformance with $\theta=\underline{q} / q<1$. We may deduce from our previous results on contract nonperformance that, under both types of moral hazard, ambiguity aversion may deter farmers from applying for a loan, although their expected profit would be positive, with an increase in the required collateral in the case of ex-ante moral hazard.

\section{Parametric insurance and credit to smallholders in Tanzania}

\subsection{Background: the Farm to Market Alliance}

The calibration of our theoretical model is based on data associated with a project piloted in Tanzania from 2016 to 2018. The background is the promotion of productive agricultural technology by the World Food Program within the Farm to Market Alliance (FtMA), as well as the development of innovative weather-index insurance products for banks operating in the agribusiness space. In practice, all rural households in Tanzania participate in agriculture, earning from it an average of $70 \%$ of their income ${ }^{13}$ However, cereal yields and agricultural labor productivity have lagged behind other countries during the last decades 14 This is largely due to low staple crop productivity, which has been linked to poor agronomic practices and limited use of modern farming techniques, as well as financial constraints such as limited access to savings, credit and insurance. Addressing individual inefficiencies has rarely resulted in material productivity boosts (see the limited success of Smart Input Subsidy Programs ${ }^{15}$, whereas integrated

\footnotetext{
${ }^{13}$ In Tanzania, income from crops is dominant, followed at a distance by livestock and agricultural wage labor (see Davis et al. 2014).

${ }^{14}$ They are still at $1464 \mathrm{~kg} / \mathrm{ha}$ and $563 \mathrm{US} \$$ per worker levels, respectively, when averaged over 2012-14, compared with a $3779 \mathrm{~kg} / \mathrm{ha}$ and 3215 US $\$$ at the world level (World Bank, 2016).

${ }^{15}$ Starting with Malawi's lead in the mid-2000s, there has been renewed interest in input subsidy programs across Africa, but it has become soon apparent they have not delivered
} 
approaches seem to be more promising. Against this background, in 2015 WFP promoted the FtMA initiative to support the sustainable growth of smallholder farms in several African countries, including Tanzania (Vandercasteelen and Christiaensen, 2018). The FtMA is a demand-driven consortium of public and private value chain stakeholders aiming to facilitate smallholder farmers' participation across entire value chains in order to raise their marketable surplus production and therefore livelihoods. In Tanzania, the FtMA decided to focus on maize production by targeting an initial pool of 75,000 smallholders during the period 2016-18. The objective was to improve the supply chain for commercial maize markets by linking Farmers Organizations (FOs) to domestic buyers (through guaranteed market access at a minimum price), as well as financial institutions (for credit provision), input providers and extension service providers (facilitated through different NGOs). Incentivizing farmers to adopt more productive technologies (draught-tolerant seed varieties, better quality fertilisers, more efficient use of inputs with reduction of acidification, etc.) was the main objective of promoting access to credit.

The extension of credit was facilitated by the bundling of a parametric insurance product ${ }^{16}$ with loan agreements, so as to help farmers service their loans in the face of adverse weather events. The first round of the Tanzanian FtMA intervention was deployed during the production year 2015-2016 and covered 21,000 farmers across 29 FOs. It was implemented in three zones and nine regions across the three main maize areas of Tanzania: a) Kilimanjaro, Manyara, Arusha in North Tanzania (6,000 farmers); b) Morogoro, Singida, Dodoma in Central Tanzania (8,000 farmers); c) Njombe, Ruvuma, and Iringa in South Tanzania (7,000 farmers). These nine regions represent Tanzania's key maize producing areas. In the production season 2016-2017, WFP expanded the scope of FtMA to reach a total target of 50,000 farmers including the 21,000 farmers who had already received the FtMA intervention in the previous year, and 29,000 new farmers deemed to be eligible to receive the intervention. The FtMA intervention provided farmers with a full set of agricultural services ranging from input credit to tailor-made input packages, forward delivery contracts, agricultural practice training, post-harvest training, aggregation centers, drying and post-harvest equipment.

the desired results, while at the same time proving to be unsustainable from a fiscal point of view; see Morris et al. (2007) and Jayne and Rashid (2013), for example.

${ }^{16}$ The insurance product was deployed by Jubilee Insurance of Tanzania with the support of Munich Re, researchers at the Brevan Howard Centre for Financial Analysis at Imperial College London, and Climate-KIC/EIT. 


\subsection{Description of the different technological scenarios}

A wide range of adaptation strategies are available to smallholder farmers to adapt to weather and climate risk as outlined in Osborne et al. (2013) and Howden et al. (2007). In this study, two technological adaptation scenarios are considered in order to simulate the change in weather-driven crop losses faced by farmers. The two adaptation strategies are: (i) the switch to a crop variety with different length of growing period (LGP); (ii) the change in amount and timing of application of fertilizer. The choice of LGP is an important factor for the adaptation of the crop variety to local hydrometeorological variability such as drought or heat waves, as illustrated by Seo (2014) for the case of smallholder farmers in sub-Saharan Africa. It enables the implementation of risk management strategies tailored to the weather hazard characteristics of the surrounding environment ${ }^{17}$ In the analysis discussed below, we allow for three types of LGP: (i) a "short" LGP of 90 days; (ii) a medium-length LGP of 120 days; (iii) a "long" LGP of 140 days. Moreover, simulations are carried out by allowing for three different levels of mixed NPK (nitrogen, phosphorus, potassium) fertilizer: (i) low fertilization of $60 \mathrm{~kg} / \mathrm{ha}$ in two applications before germination and forty days after emergence; (ii) medium fertilization of $90 \mathrm{~kg} / \mathrm{ha}$ in two applications before germination and forty days after emergence; (iii) high fertilization of $120 \mathrm{~kg} / \mathrm{ha}$ in three applications, with the first two as in (i) and (ii), and a third one at the end of the crop vegetative period. For each LGP variety, we further consider the case of a drought-tolerant cultivar and the case of no particular drought tolerance feature. This means that in each satellite pixel of interest in Tanzania, we consider a total of eighteen different technological scenarios ${ }^{18}$

\subsection{Parametric insurance mechanism}

Parametric insurance was designed on the basis of optimum rainfall indices designed to capture falls in crop yield driven by insufficient precipitation during each development stage of the crop growth. Based on these indices, the insurance payout schedule was structured so as to span the contribution of lack of rainfall to default risk. Insurance was bundled with the input loans entered into by FOs to purchase inputs for maize. Farmers paid back simultaneously the loan amount, any interest charged, as well as the insurance

\footnotetext{
${ }^{17}$ For instance, in regions with a more predictable sub-seasonal-to-inter-annual climate variability, leading for instance to a gradual build-up of increasingly adverse hydrometeorological conditions, the choice of shorter LGP varieties and earlier flowering can reduce exposure to the high-risk periods observed in sub-Saharan Africa (Vigouroux et al. 2011). Alternatively, in regions with less predictable sub-seasonal-to-seasonal and interannual climate variability (e.g., mid-latitudes), the use of varieties with longer LGPs, as well as adoption of heat resistant varieties, is considered a valuable risk coping strategy by farmers (Tao and Zhang, 2010, Moore and Lobell, 2014).

${ }^{18}$ See the Appendix for details.
} 
premium. Two banks participated in the program. They collected premiums from FOs and transferred them to the insurance company ${ }^{19}$ After taking out a loan, farmers did not receive a cash payment, but instead redeemed an e-voucher directly with their local agro-dealer in order to collect an input package ${ }^{20}$ In case of an insurance payout triggered by the index at the end of the crop season, the insurer would make a transfer directly to the bank accounts of the FOs, which would then re-distribute the payouts to the farmers affected. The payout amounts were linear in the index, conditional on the latter exceeding a pre-defined threshold, and allowed the insurance contact to cover the entire loan amount in case of maximum payout (see Biffis and Millossovich, 2012, Biffis and Chavez, 2017, and discussion therein, for similar contract payoffs). Rainfall indices were built using machine learning techniques to optimally select the variables explaining a farmer's yield. See Biffis and Chavez (2017) for further discussion and details.

\subsection{Calibration}

We calibrate our theoretical model by focusing on the case of ex-post moral hazard. Computational details, as well as description of data sources, are relegated to the appendix. We focus attention on two technologies and assume that each farmer originally used the technology with lower expected yield. The latter is characterized by (i) a "short" LGP of 90 days, (ii) low fertilisation of $60 \mathrm{~kg} / \mathrm{ha}$ in two applications before germination and forty days after emergence, and (iii) no particular drought tolerance feature. The farmer could invest $250 \$$ to acquire the technology with a higher expected yield and consisting of (i) a "long" LGP of 140 days, (ii) high fertilisation of $120 \mathrm{~kg} / \mathrm{ha}$ in three applications, and (iii) drought tolerance features. Two examples of yield distributions are presented in Figure 11 in the Appendix. For simplicity, yields have been aggregated at the country level, so that we may regard the two distributions as providing the country average yield under the two technologies ${ }^{21}$

To calibrate the model, we assume that the farmer has a level of subsistence of $2000 \mathrm{~kg} / \mathrm{ha},{ }^{22}$ and that falling below this level would result in a loan default. The project (i.e., the adoption of the technology) succeeds with probability $p$ if the farmer is able to reimburse the loan and if her yield is higher with the more costly technology than with the lower cost one, for

\footnotetext{
${ }^{19}$ Insurance coverage was provided by a large international reinsurer and a domestic insurer by using a quota-share agreement.

${ }^{20}$ Amongst the conditions to receive loans from commercial banks, FOs were required to provide a list of those members who would have used the inputs, as well as a pre-harvest contract with an off-taker guaranteeing the purchase of the crop after harvest time.

${ }^{21}$ In practice, yields were obtained at a resolution of $5 \times 5 \mathrm{~km}$ pixels; see the Appendix for further details.

${ }^{22}$ This $2000 \mathrm{~kg} / \mathrm{ha}$ subsistence level is considered for the case of a farmer whose only significant source of formal income is maize production.
} 
which no loan is needed. Computations reported in the Appendix yield a probability of failure $p=12 \%$.

The probability $q$ and the parameter $\varepsilon$ characterizing the index $\tilde{y}$ are calibrated so as to reflect the correlation between the index and the actual yields. We assume that the index $\tilde{y}$ is unbiased, in the sense that it triggers an indemnity with a probability equal to the true loss probability. This allows us to simplify the problem and write $q=p$. Finally, based on computations made in Biffis and Chavez (2017), the coefficient of correlation between the index and the actual yields of the farmers is approximately equal to 0.85 . From the model of Section 2, it is straightforward to compute the correlation coefficient of $\tilde{y}$ and $\tilde{R}$ as

$$
\rho=\varepsilon \sqrt{\frac{q(1-q)}{p(1-p)}},
$$

which simplifies to $\rho=\varepsilon$ in the case of an unbiased index, as assumed above. We can use the values of $p, q$, and $\varepsilon$ to then obtain the value of $f=p-q \varepsilon$.

The Tanzanian farmers targeted by the intervention discussed above would require a collateral in excess of $30 \%$ to be even considered for banking. We use this value to determine the collateral $C_{1}^{N}$ required in the case without insurance for a loan of amount $I=250 \$$, thus obtaining $C_{1}^{N}=250 \times 30 \%=75 \$$. This allows us to recover the implicit cost of default $F$ from equation (1) as follows:

$$
F=\frac{I(1-30 \%)+\eta}{1-p}=198.86 \$
$$

where we have assumed $\eta=0$. This calibration allows us to compute from equation (3) the level of collateral required when credit is bundled with a parametric insurance scheme, $C_{1}^{I}=54.29 \$$, which represents a reduction of $27.62 \%$ of the required collateral compared to the situation without insurance, and is in line with the $20 \%$ collateral required by banks in Tanzania when loans were extended to farmers with bundled insurance. We also obtain a large decrease in the interest rate from $r_{1}^{N}=9.55 \%$ to $r_{1}^{I}=1.26 \%$. This large decrease in the interest rate, however, does not completely offset the additional cost of insurance. In total, a farmer pays $D+P$, where $P=q D$, and we may write that the total loan cost with insurance as $D=(1+r+\alpha) I$, where $\alpha$ is the rate spread capturing the cost of insurance and is given by

$$
\alpha=q\left(1+\frac{\eta+(1-q) f F}{I}\right)
$$

which in our calibration gives $\alpha=12.15 \%$. So, the total cost of loan is $r^{I}+\alpha=13.41 \%$, which represents a 386 basis point increase relative to the no insurance case. As compensation for this increase, the farmer is exempted 
from the repayment of the loan with probability $q=0.12$, although, in such a case, she would be able to do it with probability $1-f-\varepsilon=0.132$.

The correlation between the index and the actual yield is an important ingredient of the model, since it captures the basis risk faced by a farmer. It is therefore interesting to consider variations on this parameter. The left panel of Table 2 reports the required collateral when the correlation parameter $\rho$ and the probability of loss $p$ vary.

\begin{tabular}{|c|c|c|c|c|c|c|c|c|}
\hline & 0.5 & 0.75 & 0.85 & 1 & 0.5 & 0.75 & 0.85 & 1 \\
\hline & \multicolumn{4}{|c|}{$C_{1}^{I}$} & \multicolumn{4}{|c|}{ Relative reduction (in \%) } \\
\hline 0,06 & 56,74 & 53,94 & 52,82 & 51,14 & 10,03 & 14,47 & 16,25 & 18,92 \\
\hline 0,12 & 61,64 & 56,39 & 54,29 & 51,14 & 17,82 & 24,82 & 27,62 & 31,82 \\
\hline 0,18 & 65,81 & 58,47 & 55,54 & 51,14 & 24,29 & 32,74 & 36,11 & 41,18 \\
\hline & \multicolumn{4}{|c|}{$r_{1}^{I}($ in $\%)$} & \multicolumn{4}{|c|}{$P$} \\
\hline 0,06 & 2,24 & 1,12 & 0,67 & 0,00 & 15,44 & 15,21 & 15,13 & 15,00 \\
\hline 0,12 & 4,20 & 2,10 & 1,26 & 0,00 & 31,67 & 30,81 & 30,48 & 30,00 \\
\hline 0,18 & 5,87 & 2,94 & 1,76 & 0,00 & 48,59 & 46,72 & 46,02 & 45,00 \\
\hline
\end{tabular}

Table 2: The upper left panel reports the collateral requirement $C_{1}^{I}$ with parametric insurance. The upper right panel reports the relative reduction on collateral requirement $C_{1}^{I} / C_{1}^{N}-1$. The lower left and right panels report the required interest rate $r_{1}^{I}$ and the premium $P$, respectively.

Considering a lower correlation $\rho=0.75$, for example, would result in a lower collateral reduction, as the coverage provided to the bank would be lower, and collateral requirements would fall only to $C_{2}^{I}=56.39 \$$. When the index is perfectly correlated with the loss, the bank is perfectly insured against a default. As a result, the interest rate is nil and the required collateral is independent of the loss probability $p$. In contrast, when the index is imperfect, the bank requires a positive interest rate that increases with the probability of loss $p$. As a result, the collateral required to deter a strategic default increases with $p$.

The insurance premium varies in Table 2 between $15.44 \$$ and $48.59 \$$. This highlights one limit of the mechanism proposed in this paper, particularly when the insurance premium is not subsidised. Indeed, the decrease in collateral requirements and interest rates, permitted by the bundling of loan and parametric insurance, comes from the fact that the farmer is able to mobilise non-pledgeable wealth, derived from activities in the informal sector, to pay the insurance premium. This allows to decrease the required collateral. The bundling therefore only works to the extent that farmers hold enough non-pledgeable wealth to pay the insurance premium. However, since the poorest farmers are likely to hold mainly non-pledgeable assets, 
the insurance premium is a binding constraint for those farmers who would not have had access to credit in the absence of insurance. In our model, parametric insurance is not a solution to lower the cost of borrowing, but rather to overcome the lack of pledgeable wealth among smallholder farmers in developing countries.

\section{Conclusion}

In this paper we have developed a model showing how parametric insurance bundled with loan contracts can reduce credit rationing. We have discussed an application in the context of agricultural input loans and weather-index insurance in Tanzania, highlighting the favourable effect of bundling parametric insurance with loans on the size the required collateral. Our analysis thus shows how the efficiency losses associated with imperfect insurance (basis risk) can be outweighed by a relaxation of credit rationing. The results provide support to innovative bundled finance solutions becoming more popular in East Africa and promoting access to finance among smallholder farmers lacking sufficient collateral or relevant credit history. Even-tough we are convinced that our theoretical results would remain valid in a broader setting, much remains to be done to precisely estimate the efficiency gains that may be brought by parametric insurance. This would go through a much more detailed modelling of yields and weather indices and their statistical relationship.

Our model rests on several restrictive assumptions. The assumption of risk neutrality has been made for the sake of simplicity. Assuming that farmers are risk averse would add an additional motive of demand for insurance, independently from its role in reducing the collateral and facilitating technology adoption.

Both the ex-post and ex-ante moral hazard models presented in this paper investigate the relationship between a single bank and a representative farmer. In the case of a population of heterogeneous farmers, the model and its conclusions would remain unchanged as long as the loan contract (the level of nominal debt $D$ and the collateral $C$ ) may be tailored to reflect farm-specific characteristics.

If farmers face idiosyncratic risks or if the bank is risk-neutral, the model would once again apply directly to each category of farmer and associate to each a specific contract. In contrast, the presence of bank risk aversion, due for example to increasing marginal costs of capital in the spirit of Froot et al. (1993), and of a systemic component in the risk faced by farmers would give rise to an additional motive for insurance demand from the bank. 


\section{References}

Agutu, N. O., Awange, J. L., Zerihun, A., Ndehedehe, C. E., Kuhn, M., and Fukuda, Y. (2017). Assessing multi-satellite remote sensing, reanalysis, and land surface model's products in characterizing agricultural drought in East Africa. Remote Sensing of Environment, 194:287-302.

Angelil, O., Perkins-Kirkpatrick, S., Alexander, L. V., Stone, D., Donat, M. G., Wehner, M., Shiogama, H., Ciavarella, A., and Christidis, N. (2016). Comparing regional precipitation and temperature extremes in climate model and reanalyses products. Weather and Climate Extremes, 13:35-43.

Awange, J. LAwange, K. X. and Khaki, M. (2019). The newly merged satellite reremote sensed, gauge and reanalysis-based multi-source weighted ensemble precipitation: evaluation over australia and africa (1981-2016). Science of the Total Environment, 670:448-465.

Bandiera, O. and Rasul, I. (2006). Social networks and technology adoption in northern mozambique. The Economic Journal, 116(514):869-902.

Beck, H. E., Pan, M., Roy, T., Weedom, G. P., Pappenberger, F., van Dijk, A. I. J. M., Huffman, G. J., Adler, R. F., and Wood, E. F. (2019). Daily evaluation of 26 precipitation datasets using Stage IV gauge radar data for the CONUS. Hydrology and Earth System Sciences, 23:207-224.

Biffis, E. and Chavez, E. (2017). Satellite data and machine learning for weather risk management and food security. Risk Analysis, 37(8):15081521.

Biffis, E. and Millossovich, P. (2012). Optimal insurance with counterparty default risk. SSRN Working Paper.

Bolton, P. and Scharfstein, D. S. (1990). A theory of predation based on agency problems in financial contracting. The American Economic $\underline{\text { Review, pages } 93-106 .}$

Breiman, L. (2001). Random forests. Machine Learning, 45:5-32.

Bruhn, M. and McKenzie, D. (2009). In pursuit of balance: Randomization in practice in development field experiments. American Economic Journal: Applied Economics, 1(4):200-232.

Bryan, G. (2019). Ambiguity aversion decreases the impact of partial insurance: Evidence from african farmers. Journal of the European Economic Association, 17(5):1428-1469. 
Carter, M., De Janvry, A., Sadoulet, E., Sarris, A., et al. (2014). Indexbased weather insurance for developing countries: A review of evidence and a set of propositions for up-scaling. Development Policies Working Paper, 111.

CHC-UCSB and USAID (2020). CHIRPS: Rainfall estimates from rain gauge and satellite observations. Online.

Clarke, D. J. (2016). A theory of rational demand for index insurance. American Economic Journal: Microeconomics, 8(1):283-306.

Cole, S., Giné, X., and Vickery, J. (2017). How does risk management influence production decisions? Evidence from a field experiment. The Review of Financial Studies, 30(6):1935-1970.

Conway, G. and Toenniessen, G. (1999). Feeding the world in the twentyfirst century. Nature, 402(6761):C55-C58.

Cullen, A. C. and Anderson, C. L. (2016). Perception of climate risk among rural farmers in Vietnam: Consistency within households and with the empirical record. Risk Analysis, 37(3):531-545.

Cummins, J. D. and Mahul, O. (2003). Optimal insurance with divergent beliefs about insurer total default risk. Journal of Risk and Uncertainty, 27(2):121-138.

Davis, B., Di Giuseppe, S., and Zezza, A. (2014). Income diversification patterns in rural sub-Saharan Africa. Reassessing the evidence. World Bank: Washington.

Dercon, S. and Christiaensen, L. (2011). Consumption risk, technology adoption and poverty traps: Evidence from Ethiopia. Journal of Development Economics, 96(2):159-173.

Dewatripont, M. and Maskin, E. (1995). Credit and efficiency in centralized and decentralized economies. The Review of Economic Studies, 62(4):541555 .

Diamond, D. W. (1984). Financial intermediation and delegated monitoring. The Review of Economic Studies, 51(3):393-414.

Doherty, N. A. and Schlesinger, H. (1991). Rational insurance purchasing: consideration of contract non-performance. In Managing the Insolvency Risk of Insurance Companies, pages 283-294. Springer.

Duflo, E., Kremer, M., and Robinson, J. (2008). How high are rates of return to fertilizer? Evidence from field experiments in Kenya. American Economic Review, 98(2):482-88. 
Duflo, E., Kremer, M., and Robinson, J. (2011). Nudging farmers to use fertilizer: Theory and experimental evidence from Kenya. American Economic Review, 101(6):2350-90.

ECMWF (2020). ERA-Interim. European Centre for Medium-Range Weather Forecasts, https://www.ecmwf.int/en/forecasts/datasets/ reanalysis-datasets/era-interim

Evenson, R. E. and Gollin, D. (2003). Assessing the impact of the Green Revolution, 1960 to 2000. Science, 300(5620):758-762.

Feder, G. and Umali, D. L. (1993). The adoption of agricultural innovations: A review. Technological Forecasting and Social Change, 43(3-4):215-239.

Foster, A. D. and Rosenzweig, M. R. (1995). Learning by doing and learning from others: Human capital and technical change in agriculture. Journal of Political Economy, 103(6):1176-1209.

Freebairn, D. K. (1995). Did the Green Revolution concentrate incomes? A quantitative study of research reports. World Development, 23(2):265279 .

Froot, K. A., Scharfstein, D. S., and Stein, J. C. (1993). Risk management: Coordinating corporate investment and financing policies. The Journal of Finance, 48(5):1629-1658.

Funk, C., Peterson, P., Landseld, M., Pedredos, D., Verdin, J., Shukla, S., Husak, G., Rowland, J., Harrison, L., Hoell, A., and Michaelsen, J. (2015). The Africa hazards infraared precipitation with stations - a new environmental record for monitoring extremes. Nature Scientific Data, $2: 1-21$.

Gebrechorkos, S. H., Hulsmann, S., and Bernhofer, C. (2018). Evaluation of multiple climate data sources for managing environmental resources in east africa. Hydrology and Earth System Sciences, 22:4547-4564.

Gilboa, I. and Schmeidler, D. (1989). Maxmin expected utility with a nonunique prior.

Giné, X. and Yang, D. (2009). Insurance, credit, and technology adoption: Field experimental evidencefrom Malawi. Journal of Development Economics, 89(1):1-11.

Gromb, D. (1994). Contributions a l'economie financiere et industrielle. $\mathrm{PhD}$ thesis. Thèse de doctorat dirigée par Bolton, P. Sciences Appliquées Palaiseau, Ecole Polytechnique 1994. 
Gross, M. H., Donaat, M. G., and Alexander, L. V. (2018). The sensitivity of daily temperature variability and extremes to dataset choice. Journal of Climate, 31:1337-1358.

Hastie, T., Friedman, J., and Tibshirani, R. (2001). The elements of statistical learning. Springer Series in Statistics. Springer, Berlin.

Hill, R. V., Kumar, N., Magnan, N., Makhija, S., de Nicola, F., Spielman, D. J., and Ward, P. S. (2019). Ex-ante and ex-post effects of hybrid index insurance in Bangladesh. Journal of Development Economics, 136:1-17.

Holmstrom, B. and Tirole, J. (1997). Financial intermediation, loanable funds, and the real sector. The Quarterly Journal of Economics, 112(3):663-691.

Howden, S. M., Soussana, J.-F., Tubiello, F. N., Chhetri, N., Dunlop, M., and Meinke, H. (2007). Adapting agriculture to climate change. Proceedings of the National Academy of Science, 104(50):19961-19696.

Jaffee, D. M. and Russell, T. (1976). Imperfect information, uncertainty, and credit rationing. The Quarterly Journal of Economics, 90(4):651-666.

Jayne, T. S. and Rashid, S. (2013). Input subsidy programs in sub-Saharan Africa: A synthesis of recent evidence. Agricultural Economics, 44(6):547562.

Jones, J. W., Hoogenboom, G., Porter, C. H., Boote, H. J., Batchelor, W. D., Hunt, L. A., Wilkens, P. W., Singh, U., Gijsman, A. J., and Ritchie, J. T. (2003). The DSSAT cropping system model. European Journal of Agronomy, 18:235-265.

Karlan, D., Osei, R., Osei-Akoto, I., and Udry, C. (2014). Agricultural decisions after relaxing credit and risk constraints. The Quarterly Journal of Economics, 129(2):597-652.

Le Coz, C. and van de Giesen, N. (2020). Comparison of rainfall products over sub-Saharan Africa. Journal of Hydrometeorology, 21:553-596.

McIntosh, C., Sarris, A., and Papadopoulos, F. (2013). Productivity, credit, risk, and the demand for weather index insurance in smallholder agriculture in Ethiopia. Agricultural Economics, 44(4-5):399-417.

Moore, F. and Lobell, D. B. (2014). Adaptation potential of European agriculture in response to climate change. Nature Climate Change, 4:610614.

Morris, M., Kelly, V. A., Kopicki, R. J., and Byerlee, D. (2007). Fertilizer use in African agriculture: Lessons learned and good practice guidelines. The World Bank. 
Munday, C. and Washington, R. (2018). Systematic climate model rainfall biases over Sourthern Africa: Links to moisture circulation and topography. Journal of Climate, 31:7533-7548.

Ndegwa, M. K., Shee, A., Turvey, C. G., and You, L. (2019). Uptake of insurance-embedded credit in presence of credit rationing: Evidence from a randomized controlled trial in Kenya.

Osborne, T., Rose, G., and Wheeler, T. (2013). Variation in the global-scale impacts of climate change on crop productivity due to climate model uncertainty and adaptation. Agricultural and Forest Meteorology, 170:183194.

Parente, S. L. and Prescott, E. C. (1994). Barriers to technology adoption and development. Journal of Political Economy, 102(2):298-321.

Parkes, B., Higginbottim, T. P., Hufkens, K., Ceballos, F., Kramer, B., and Foster, T. (2019). Weather dataset choice introduces uncertainty to estimates of crop yield response to climate variability and change. Environmental Research Letters, 14:1-11.

Peter, R. and Ying, J. (2019). Do you trust your insurer? ambiguity about contract nonperformance and optimal insurance demand. Journal of Economic Behavior \& Organization.

Pingali, P. L. (2012). Green revolution: impacts, limits, and the path ahead. Proceedings of the National Academy of Sciences, 109(31):12302-12308.

Rosenzweig, C., Elliott, J., Derying, D., Ruane, Al, C., Muller, C., Arneth, C., Boote, K. J., Folberth, C., Glotter, M., Khabarov, N., Neumann, K., Piontek, F., Pugh, T. A. M., Schmid, E., Sterhfest, E., Ynag, H., and Jones, J. W. (2014). Assessing agricultural rrisk of climate change in the 21st century in a global gridded crop model intercomparison. Proceedings of the National Academy of Science, 111(9):3268-3273.

Sacks, W. J., Derying, D., Foley, J. A., and Ramankutty, N. (2010). Crop planting dates: An analysis of global patterns. Global Ecology and Biogeography, 19:507-620.

Satge, F., Defrance, D., Sultan, B., Bonnet, M.-P., Seyler, F., Rouche, N., Pierron, F., and Paturel, J.-E. (2020). Evaluation of 23 dgridded precipitation datasets across West Africa. Journal of Hydrology, 581:1-19.

Seo, S. N. (2014). Evaluation of the agro-ecological zone methods for the study of climate change with micro farming decisions in sub-Saharan Africa. European Journal of Agronomy, 52:157-165. 
Shee, A. and Turvey, C. G. (2012). Collateral-free lending with riskcontingent credit for agricultural development: Indemnifying loans against pulse crop price risk in India. Agricultural Economics, 43(5):561574.

Stiglitz, J. E. and Weiss, A. (1981). Credit rationing in markets with imperfect information. The American Economic Review, 71(3):393-410.

Strobl, C., Boulesteix, A., and Augustin, T. (2007). Unbiased split selection for classification trees based on the Gini index. Computational Statistics and Data Analysis, 52:483-501.

Suri, T. (2011). Selection and comparative advantage in technology adoption. Econometrica, 79(1):159-209.

Tao, F. and Zhang, Z. (2010). Adaptation of maize production to climate change in North China Plain: Quantify the relative contributions of adaptation options. European Journal of Agronomy, 33:103-116.

Vandercasteelen, J. and Christiaensen, L. (2018). Baseline report - smallholder impact evaluation of maize value chain development in Tanzania. The World Bank Group - Let's Work Tanzania.

Vigouroux, Y., Mariac, C., De Mita, S., Pham, J.-L., Gerard, B., Kapran, I., Sagnard, F., Deu, M., Chantereau, J., Ali, A., Ndjeunga, J., Luong, V., Thuillet, A.-C., Saidou, A.-A., and Bezancon, G. (2011). Selection of earlier flowering crop associated with climatic variations in the Sahel. Plos One, 6(5):1-9.

World Bank (2016). World bank development indicators 2016. (English). World Development Indicators. Washington, D.C. : World Bank Group.

Zhan, W., Guan, K., Sheffield, J., and Wood, E. F. (2016). Depiction of drought over sub-Saharan Africa unsing reanalyses precipitation data sets. Journal of Geophysical Research: Atmospheres, 10:1-20. 


\section{APPENDIX}

\section{A Discretization of the yield distribution}

Consider two technological scenarios indexed by $h=1,2$, with random crop yields $\widetilde{z}_{h}$ (in $\mathrm{kg} / \mathrm{ha}$ ). The susbsistence level yield is $z_{0}$, with $z_{0}=2000 \mathrm{~kg} / \mathrm{ha}$ assumed in our calibration. Let $\Delta \widetilde{z}$ denote the difference in the excess of the yield above $z_{0}$ when we move from the original technology with yield $\widetilde{z}_{1}$ to the new technology with yield $\widetilde{z}_{2}$. . We have $\Delta \widetilde{z}=\left(\widetilde{z}_{2}-z_{0}\right)^{+}-\left(\widetilde{z}_{1}-z_{0}\right)^{+}$ and hence:

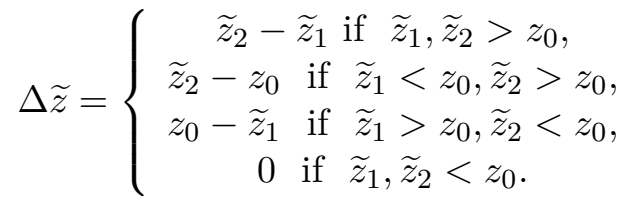

We then define $R$ and $p$ as follows:

$$
\begin{aligned}
R & =\mathbb{E}[\Delta \widetilde{z} \mid \Delta \widetilde{z}>0] \\
p & =\mathbb{P}(\Delta \widetilde{z}>0)
\end{aligned}
$$

The distributions of yields illustrated in the following sections demonstrate that moving from the old to the new technology increases the expected value and the variance of the yield. Denoting by $(\mathcal{S}, \mathcal{F}, \mathbb{P})$ the reference probability space, we may write $\widetilde{z}_{2}(s)=\varphi\left(s, \widetilde{z}_{1}(s)\right), s \in \mathcal{S}$, for some measurable function $\varphi$. For simplicity, we decided to consider the special case in which $\varphi$ is a deterministic linear function ${ }^{23}$ We write $\widetilde{z}_{2}=\lambda \widetilde{z}_{1}$ a.s. for some $\lambda \in \mathbb{R}$ to be estimated from the data. After some computations we, obtain

$$
\begin{aligned}
R=\frac{1}{p}\{ & (\lambda-1) \mathbb{E}\left[\widetilde{z}_{1} \mid \widetilde{z}_{1}>z_{0}\right] \mathbb{P}\left(\widetilde{z}_{1}>z_{0}\right) \\
& \left.+\mathbb{E}\left[\lambda \widetilde{z}_{1}-z_{0} \mid \widetilde{z}_{1}<z_{0}<\lambda \widetilde{z}_{1}\right] \mathbb{P}\left(\widetilde{z}_{1}<z_{0}<\lambda \widetilde{z}_{1}\right)\right\}
\end{aligned}
$$

where we have $p=\mathbb{P}\left(\lambda \widetilde{z}_{1}>z_{0}\right)$.

\section{B Crop model computations}

\section{B.1 Model description.}

Several types of crop models are available to assess the response of crop yield to environmental and meteorological variability. Deterministic crop models incorporate different coupled modules that represent the soil-plantatmosphere continuum. Each module is designed as a separate and individual model that predicts the dynamics of each component of the system. The

\footnotetext{
${ }^{23}$ The extension to an affine function produces very similar results.
} 
framework allows researchers to model the physiological response of a crop at a daily time step to environmental and meteorological variability. Such crop models can be used to carry out regional-level simulations on gridded data (e.g., Rosenzweig et al., 2014), exactly as we do here. Deterministic models also allow us to analyze different technological and management scenarios, such as changes in seed variety or fertilizer application. The outputs of a mechanistic crop model called Decision Support System for Agro-technology Transfer (DSSAT) (see Jones et al. 2003) are used to produce the results reported below.

\section{B.2 Meteorological variables and choice of datasets.}

Seven daily hydro-meteorological variables are needed to simulate crop yield (total precipitation, maximum and minimum temperature, average relative humidity, mean solar radiation, average wind speed, total evapotranspiration). Precipitation and temperature variability rank as the most important drivers of crop yield. The choice of weather datasets has been shown to introduce uncertainty in the yield estimates produced by crop models (e.g., Parkes et al., 2019). However, systematic studies focused on assessing such data bias are scarce and incomplete for regions with poor historical records such as sub-Saharan Africa (Gross et al., 2018). Different studies have been carried out to characterise the biases and skills of various available precipitation reanalysis products (e.g., Beck et al., 2019), both globally and for sub-Saharan Africa. The review carried out by Le Coz and van de Giesen (2020), in particular, indicates that the choice of precipitation data depends on the application intended with some approaches offering better skill for flood monitoring and others for agricultural drought. Gebrechorkos et al. (2018) compare the skill of three widely used precipitation reanalysis products in Eastern Africa (Ethiopia, Kenya, and Tanzania) to reproduce statistics of daily cumulative rainfall and find the Climate Hazards Infrared Precipitation with Stations (CHIRPS) to have the greatest accuracy, while Satge et al. (2020) conclude that CHIRPS is one of the two top performers in West Africa. Agutu et al. (2017) carry out a similar analysis, focusing on the ability of different products to assess agricultural drought in Eastern Africa and similarly identify CHIRPS as having the the highest performance.

Given these assessments, the daily precipitation is retrieved from the CHIRPS database (CHC-UCSB and USAID, 2020, Funk et al., 2015), while the six remaining were accessed for consistency from a single source from the European Centre for Medium-Range Weather Forecasts (ECMWF) ERAInterim reanalysis data online repository (ECMWF, 2020). ERA-Interim variables are aggregated to produce the relevant daily statistics (average, maximum, and minimum values) and interpolated on the $5 \times 5 \mathrm{~km}^{2}$ CHIRPS grid using bilinear interpolation. Finally, the crop model simulations were carried out based on the planting window datasets from the SAGE database 
of the University of Wisconsin (see Sacks et al., 2010).

\section{B.3 Numerical results}

General results. The simulations are based on the meteorological datasets described in the previous sub-section and capture the eighteen different technological scenario calibrations outlined in the paper. Time series of corn yield for the 1983-2013 period were obtained. Left zero-truncated normal distributions were fitted to the pixel-level yield model output data for different levels of spatial aggregation. Figure 9 displays the probability density functions (top panel) and cumulative density functions (bottom panel) obtained at country-level over 7,494 pixels of size $5 \times 5 \mathrm{~km}^{2}$. We consider $2,000 \mathrm{~kg} / \mathrm{ha}$ as the minimum corn yield required for a household to ensure subsistence needs, and hence the loan default boundary. Only production above this threshold can thus be sold to the market to generate proceeds to refund a contracted input loan. We observe that the probability of loan default varies from $2 \%$ to $28 \%$ depending on the technology used. For comparison, and to give some idea of the geographical heterogeneity of crop yield's distribution, we report in Figure 10 the aggregate distribution of corn yield subject to the different technological scenarios for the Central region of Tanzania (between $-5^{\circ}$ and $-8^{\circ} \mathrm{N}$ latitude).

Crop yield sensitivity to different technologies. As discussed in the paper, we consider three types of technology: (i) change from short to long LGP varieties; (ii) a change to drought-tolerance varieties; (iii) a change from low to high use of nitrogen fertiliser. We observe that the most important driver of variability of average and variance yield is the LGP. Figure 9 and Figure 10 both show that at country and regional level, the LGP dominates the response of interannual yield variability. Both average yield and variance increase from the lowest country-level average yield of 2,521 $\mathrm{kg} / \mathrm{ha}$ and standard deviation of $652 \mathrm{~kg} / \mathrm{ha}$ for a scenario of short LGP, 60 $\mathrm{kg} / \mathrm{ha}$ of nitrogen fertiliser, and no drought tolerance, to the highest countrylevel average yield of $5,245 \mathrm{~kg} / \mathrm{ha}$ with standard deviation of $2,296 \mathrm{~kg} / \mathrm{ha}$ when adopting a long LGP variety with $120 \mathrm{~kg} / \mathrm{ha}$ of nitrogen fertiliser and drought tolerance features. On average, at country-level, the standard deviation is equal to $34 \%$ of the average yield for long growing period varieties compared with $22 \%$ for short growing season varieties. This pattern is consistent across North (north of $-5^{\circ} \mathrm{N}$ latitude), Central, and Southern (South of $-8^{\circ} \mathrm{N}$ latitude) Tanzania.

This can be interpreted as follows: in comparison to a short LGP maize variety, a maize variety with long LGP is more subject to weather extremes (such as drought, heat, and cold) that can potentially increase its yield variability. In Tanzania, for instance, the end of the rainy reason can coincide with the end of a long growing period for maize. When the growing period 
increases, not only a higher yield potential arises, but also a higher probability of the grain filling phase to be affected by higher temperatures or drought at the end of the growing season, which can result in a drop in yield.

Finally, Figures 11 and 12 illustrate the effect of the subsistence threshold. Considering a $1050 \mathrm{~kg} / \mathrm{ha}$ subsistence instead of a $2000 \mathrm{~kg} /$ ha threshold induces a reduction in the default probability from $24 \%$ to $0.7 \%$ in the absence of the technology package and from $2.5 \%$ to $0 \%$ with the technology. 

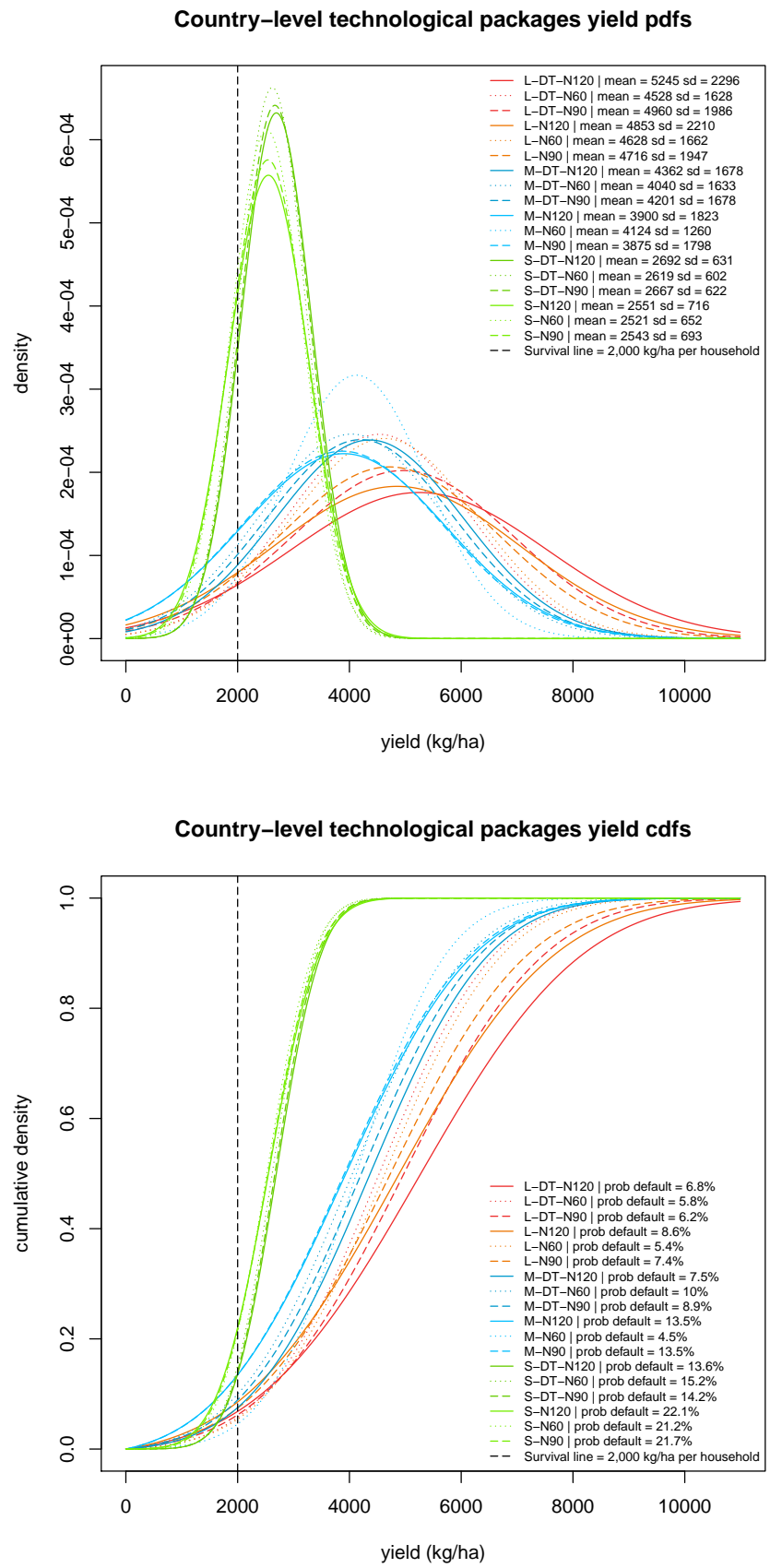

Figure 9: Country-level distributions of corn yield by technology. We consider eighteen technological scenarios in Tanzania. The top panel displays the pdfs of left zero-truncated normal distributions of corn yields and the bottom panel displays the corresponding cdfs. The legend reports the probability of loan default corresponding to the probability of not attaining a minimum household subsistence-level yield of 2,000 $\mathrm{kg} / \mathrm{ha}$. 


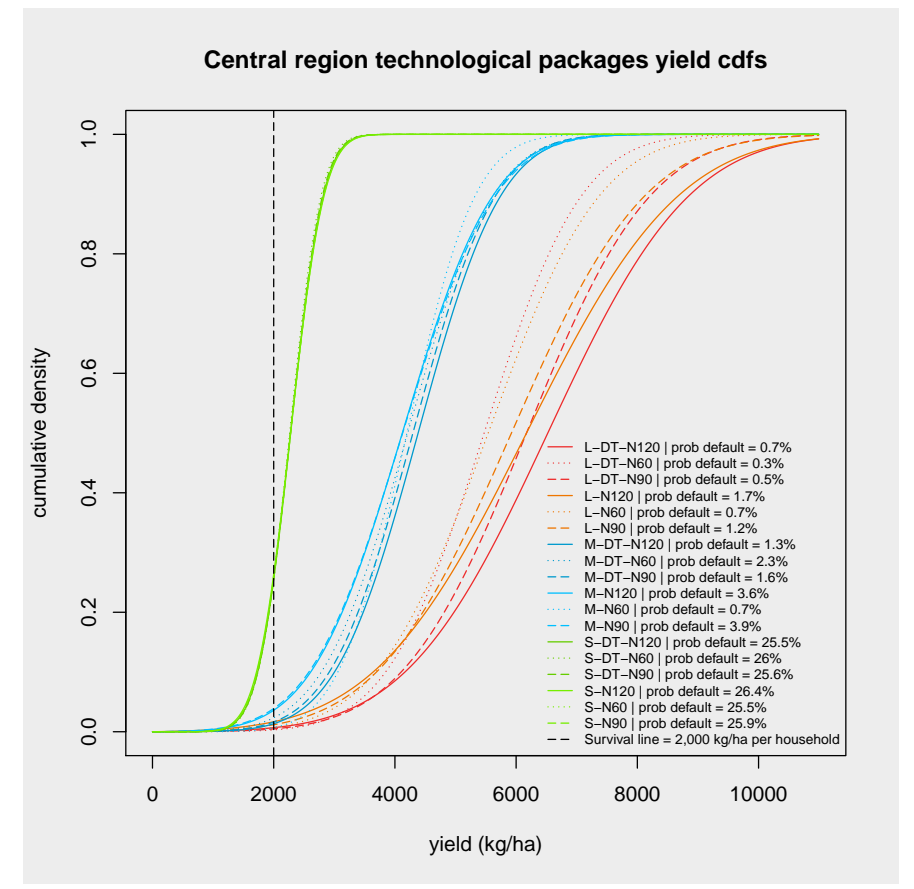

Figure 10: Region-level distributions of corn yield for different technologies. We consider eighteen technological scenarios in Tanzania. The chart displays as an example the cdf's in the region located between $-5^{\circ}$ and $-8^{\circ} \mathrm{N}$ latitude. The legend reports the probability of loan default corresponding to the probability of not attaining a minimum household subsistence level equal to a yield of $2,000 \mathrm{~kg} / \mathrm{ha}$. 

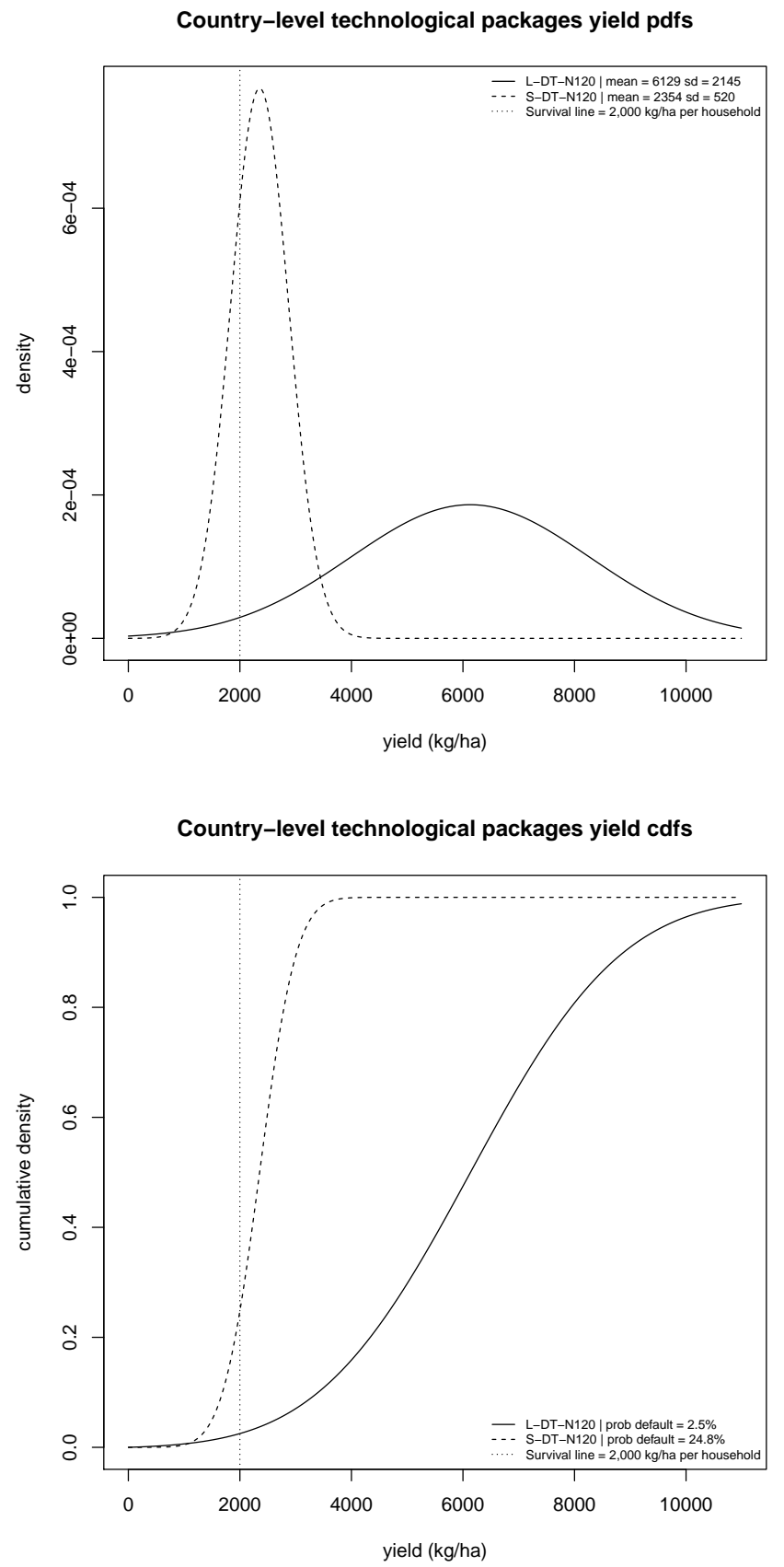

Figure 11: Country-level distributions of corn yield obtained subject to two technological scenarios in Tanzania. We consider short and long LGPs with drought tolerance traits and application of $120 \mathrm{~kg}$ of nitrogen fertilizer. The top chart displays the pdf's of left zero-truncated Normal distributions of corn yields, whereas the bottom panel displays the corresponding cdf's. The legend of the cdf chart reports the probability of loan default corresponding to the probability of not attaining a minimum household subistence-level yield of $2,000 \mathrm{~kg} / \mathrm{ha}$. 

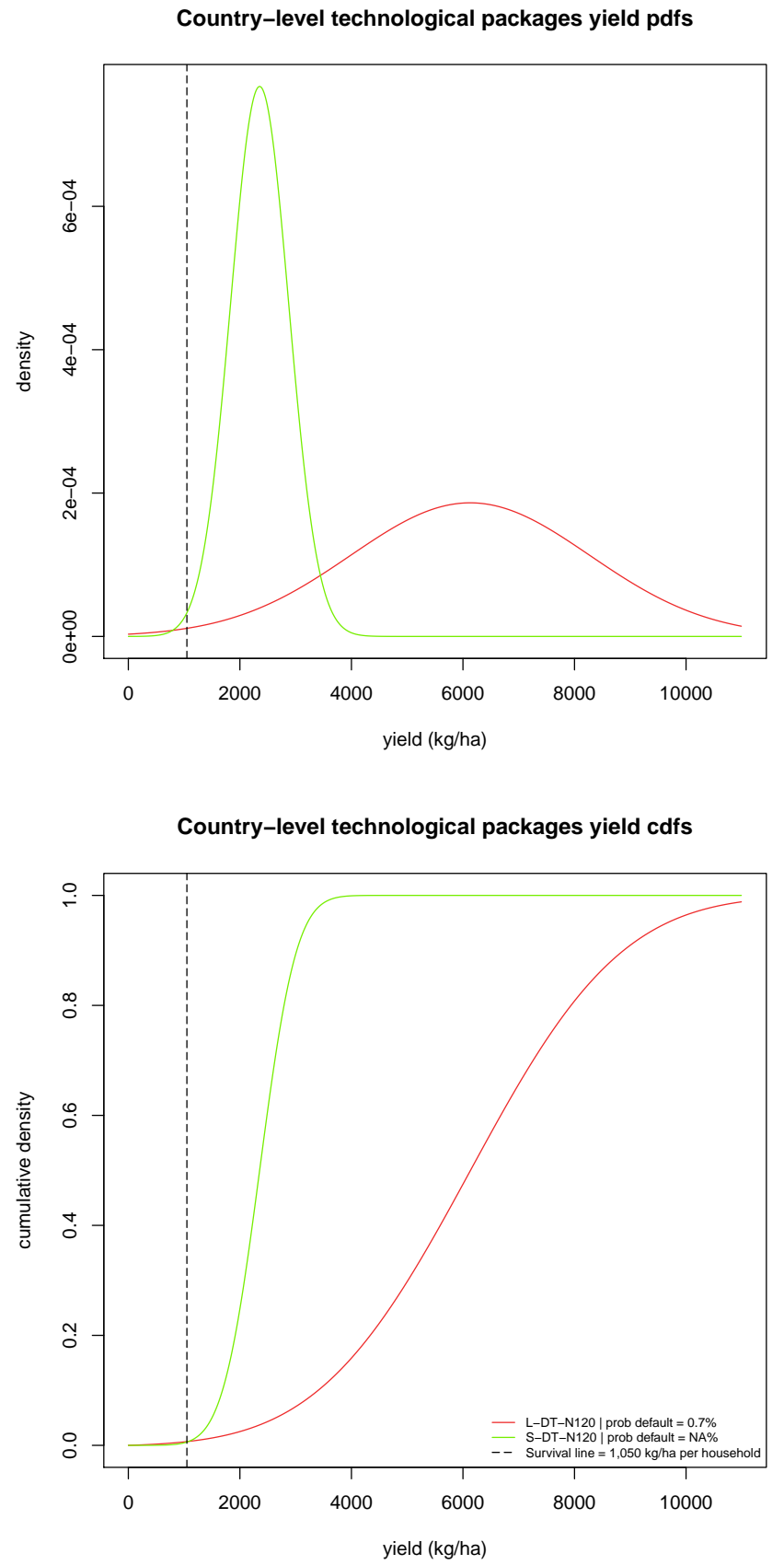

Figure 12: Country-level distributions of corn yield obtained subject to two technological scenarios in Tanzania. We consider short and long LGPs with drought tolerance traits and $120 \mathrm{~kg}$ of nitrogen fertilizer applied. The top chart displays the pdf's of left zero-truncated normal distributions of corn yields, whereas the bottom panel displays the corresponding cdf's. The legend of the cdf chart reports the probability of loan default corresponding to the probability of not attaining a minimum household subistence-level yield of $1,050 \mathrm{~kg} / \mathrm{ha}$. 